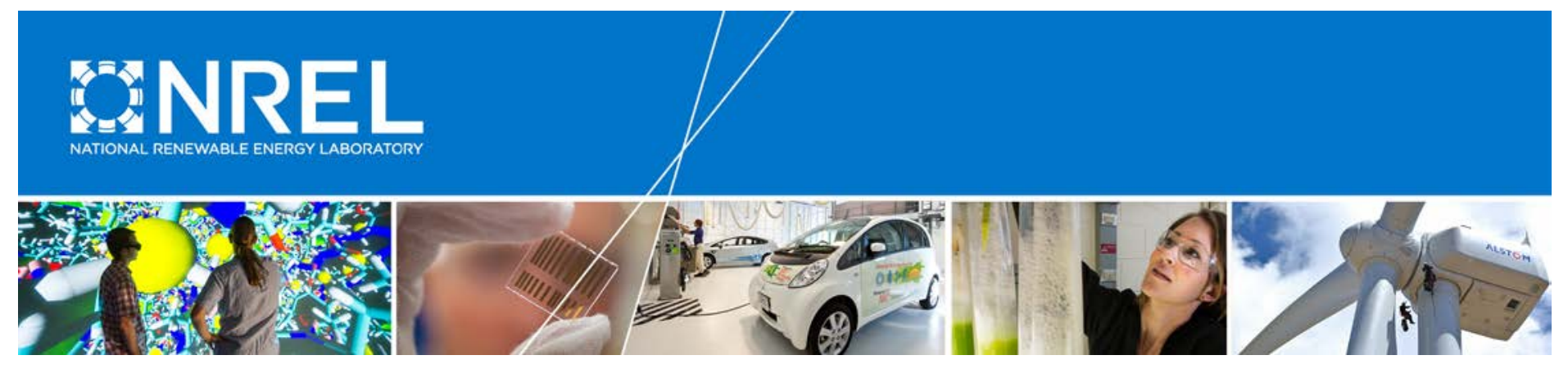

\title{
Exploring the Potential \\ Competitiveness of Utility-Scale \\ Photovoltaics plus Batteries \\ with Concentrating Solar Power, \\ 2015-2030
}

David Feldman, Robert Margolis, and

Paul Denholm

National Renewable Energy Laboratory

Joseph Stekli

U.S. Department of Energy

NREL is a national laboratory of the U.S. Department of Energy

Office of Energy Efficiency \& Renewable Energy

Operated by the Alliance for Sustainable Energy, LLC

This report is available at no cost from the National Renewable Energy

Laboratory (NREL) at www.nrel.gov/publications.

Technical Report

NREL/TP-6A20-66592

August 2016

Contract No. DE-AC36-08G028308 


\section{Exploring the Potential Competitiveness of Utility- Scale Photovoltaics plus Batteries with Concentrating Solar Power, 2015-2030}

David Feldman, Robert Margolis, and Paul Denholm

National Renewable Energy Laboratory

Joseph Stekli

U.S. Department of Energy

Prepared under Task No. ST6B.0110

NREL is a national laboratory of the U.S. Department of Energy Office of Energy Efficiency \& Renewable Energy Operated by the Alliance for Sustainable Energy, LLC

This report is available at no cost from the National Renewable Energy Laboratory (NREL) at www.nrel.gov/publications.

National Renewable Energy Laboratory 15013 Denver West Parkway Golden, CO 80401

303-275-3000 • www.nrel.gov
Technical Report

NREL/ TP-6A20-66592

August 2016

Contract No. DE-AC36-08GO28308 


\section{NOTICE}

This report was prepared as an account of work sponsored by an agency of the United States government. Neither the United States government nor any agency thereof, nor any of their employees, makes any warranty, express or implied, or assumes any legal liability or responsibility for the accuracy, completeness, or usefulness of any information, apparatus, product, or process disclosed, or represents that its use would not infringe privately owned rights. Reference herein to any specific commercial product, process, or service by trade name, trademark, manufacturer, or otherwise does not necessarily constitute or imply its endorsement, recommendation, or favoring by the United States government or any agency thereof. The views and opinions of authors expressed herein do not necessarily state or reflect those of the United States government or any agency thereof.

This report is available at no cost from the National Renewable Energy Laboratory (NREL) at www.nrel.gov/publications.

Available electronically at SciTech Connect http:/www.osti.gov/scitech

Available for a processing fee to U.S. Department of Energy and its contractors, in paper, from:

U.S. Department of Energy

Office of Scientific and Technical Information

P.O. Box 62

Oak Ridge, TN 37831-0062

OSTI http://www.osti.gov

Phone: 865.576.8401

Fax: 865.576.5728

Email: reports@osti.gov

Available for sale to the public, in paper, from:

U.S. Department of Commerce

National Technical Information Service

5301 Shawnee Road

Alexandria, VA 22312

NTIS http://www.ntis.gov

Phone: 800.553 .6847 or 703.605 .6000

Fax: 703.605.6900

Email: orders@ntis.gov 


\section{Acknowledgments}

The authors wish to thank the U.S. Department of Energy (DOE) for the sponsorship and guidance of this work. We also appreciate the critical reviews by the following individuals, which greatly improved and informed the analysis contained herein:

- Paul Basore, DOE

- Nate Blair, National Renewable Energy Laboratory (NREL)

- Jenny Chase, Bloomberg New Energy Finance

- Ted James, Pacific Gas \& Electric

- Parthiv Kurup, NREL

- Minh Le, DOE

- Mark Mehos, NREL

- David Mooney, NREL

- Henry Price, Solar Dynamics LLC

- Craig Turchi, NREL 


\section{Table of Contents}

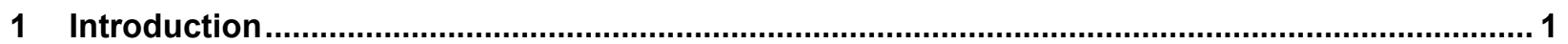

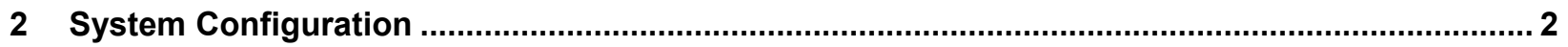

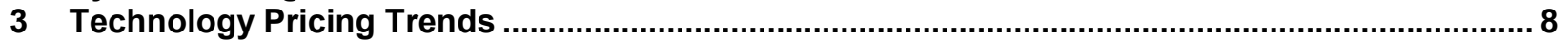

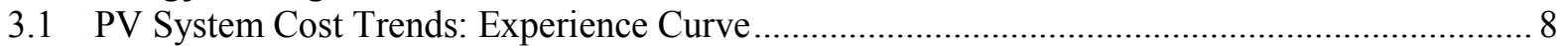

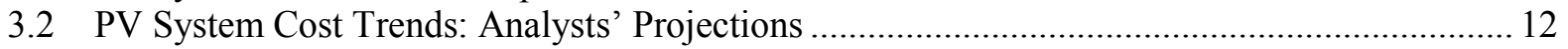

3.3 PV System Price: Comparison of Results Using Different Methodologies ............................... 14

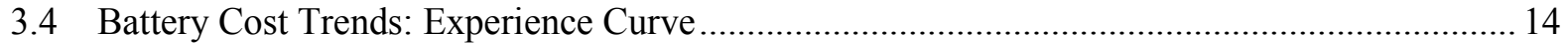

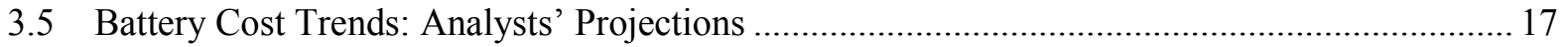

3.6 Battery System Price: Comparison of Results Using Different Methodologies ........................ 19

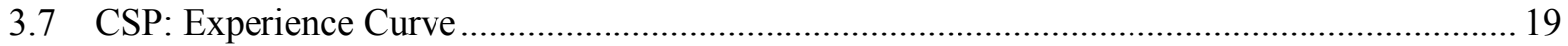

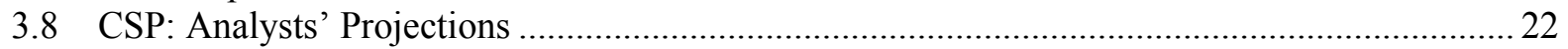

3.9 CSP System Price: Comparison of Results Using Different Methodologies ............................ 23

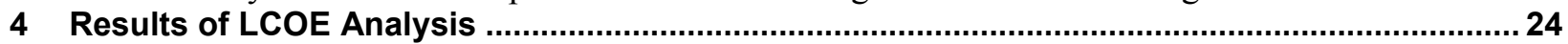

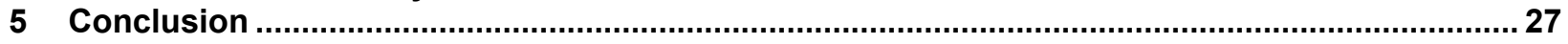

References 


\section{List of Figures}

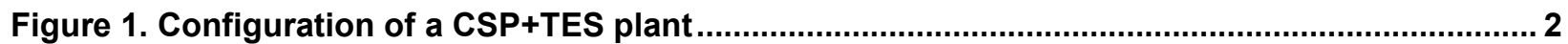

Figure 2. Impact of the SM on the energy flow of a CSP plant...................................................... 3

Figure 3. Relationship between SM and capacity factor/LCOE.......................................................... 4

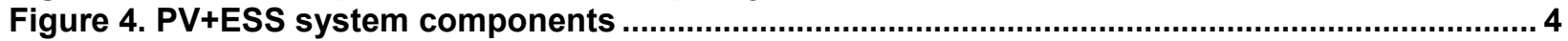

Figure 5. Relationship between capacity factor and inverter loading ratio with different amounts of

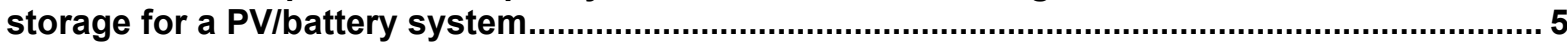

Figure 6. Experience curve for PV modules, 1976-2014.............................................................. 9

Figure 7. Projected cumulative global PV module shipments, 2012-2030 .................................... 9

Figure 8. Projected PV module price using historical experience curve, 2010-2030 ....................... 10

Figure 9. Experience curve for U.S. utility-scale PV BOS, 2010-2015.......................................... 11

Figure 10. Projected U.S. utility-scale PV deployment, 2014-2030 ............................................ 12

Figure 11. Projected U.S. utility-scale system prices, 2015-2030 ..................................................... 13

Figure 12. Projected utility-scale PV system prices from historical experience curves and

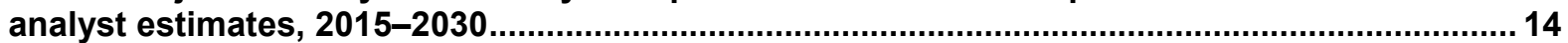

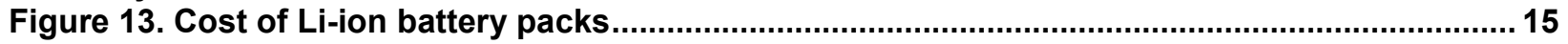

Figure 14. Modelled experience curves for battery packs............................................................. 15

Figure 15. Projected battery-pack deployment, 2010-2030 ..................................................... 16

Figure 16. Projected U.S. stationary storage deployment, 2015-2030

Figure 17. Price estimates for Li-ion battery pack, 2015-2030 ................................................... 18

Figure 18. Estimated battery BOS costs, 2015-2030 ................................................................... 18

Figure 19. Projected battery system prices from historical experience curves and analyst

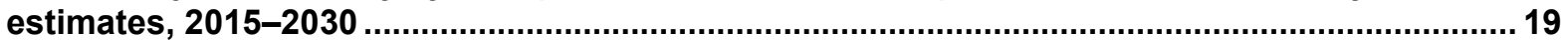

Figure 20. Installed cost of individual CSP plants over time ............................................................ 20

Figure 21. Experience curve of CSP projects, by developer, amount of storage, and location ....... 20

Figure 22. Global CSP deployment projections, 2014-2030..................................................... 21

Figure 23. Projected CSP system prices, 2015-2030 ....................................................................... 22

Figure 24. CSP system price projections from historical experience curves and analyst estimates, 2015-2030.

Figure 25. LCOE comparison: CSP versus PV (three hours of storage), 2015-2030 ...................... 25

Figure 26. LCOE comparison: CSP versus PV (six hours of storage), 2015-2030 ........................ 25

Figure 27. LCOE comparison: CSP versus PV (nine hours of storage), 2015-2030 ........................ 26 


\section{List of Tables}

Table 1. Energy Flow of 100-MW $\mathrm{AC}$ PV+ESS System with Differing Levels of PV System

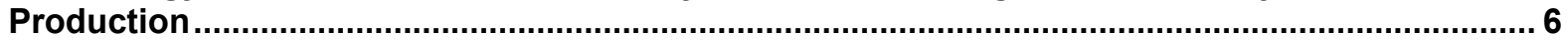

Table 2. Summary of System Configuration Assumptions ....................................................... 6

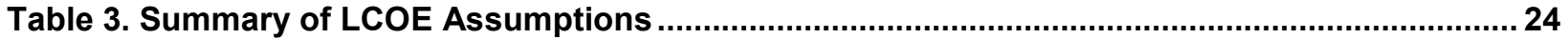




\section{Introduction}

Declining costs of both solar photovoltaics (PV) and battery storage have raised interest in the creation of "solar-plus-storage" systems to provide dispatchable energy and reliable capacity. There has been limited deployment of PV-plus-energy storage systems (PV+ESS), and the actual configuration and performance of these systems for dispatchable energy are in the early stages of being defined. In contrast, concentrating solar power with thermal energy storage (CSP+TES) has been deployed at scale with the proven capability of providing a dispatchable, reliable source of renewable generation.

A key question moving forward is how to compare the relative costs and benefits of PV+ESS and CSP+TES. While both technologies collect solar radiation and produce electricity, they do so through very different mechanisms, which creates challenges for direct comparison. Nonetheless, it is important to establish a framework for comparison and to identify cost and performance targets to aid meeting the nation's goals for clean energy deployment.

In this paper, we provide a preliminary assessment comparing the cost of energy from CSP+TES and PV+ESS that focuses on a single metric: levelized cost of energy (LCOE). We begin by defining the configuration of each system, which is particularly important for PV+ESS systems. We then examine a range of projected cost declines for PV, batteries, and CSP. Finally, we summarize the estimated LCOE over a range of configuration and cost estimates.

We conclude by acknowledging that differences in these technologies present challenges for comparison using a single performance metric. We define systems with similar configurations in some respects. In reality, because of inherent differences in CSP+TES and PV+ESS systems, they will provide different grid services and different value. For example, depending on its configuration, a PV+ESS system may provide additional value over CSP+TES by providing more flexible operation, including certain ancillary services and the ability to store off-peak grid energy. Alternatively, direct thermal energy storage allows a greater capture of solar energy, reducing the potential for curtailments in very high solar scenarios. So while this analysis evaluates a key performance metric (cost per unit of generation) under a range of cost projections, additional analysis of the value per unit of generation will be needed to comprehensively assess the relative competitiveness of solar energy systems deployed with energy storage. 


\section{System Configuration}

We begin by establishing a set of system configurations that are similar in terms of annual energy production, which for a solar-plus-storage system is defined by the quality of the solar resource as well as several plant design parameters. Because the concepts and nomenclature of solar-plus-storage plant configurations are well established for CSP+TES, we will use a discussion of CSP+TES in this section to frame our analysis of PV+ESS.

A CSP+TES plant consists of a solar collector, receiver, thermal storage, and power block. The reflective solar collectors (typically heliostats or parabolic troughs) direct solar radiation to a receiver, transferring this energy to a heat transfer fluid. The heated fluid is sent to storage, or to the power block, which converts thermal energy to electricity. An important element of a CSP+TES plant is whether it uses "direct" or "indirect" storage. For direct storage configurations, the storage medium is the same as the heat transfer fluid, and as a result, all solar energy collected by the receiver can be placed into storage. Indirect storage configurations use an intermediate heat exchanger to transfer thermal energy from the heat transfer fluid to the storage medium. Consequently, the amount of energy placed into storage depends on the heat exchanger sizing. This will have an impact on the overall plant's utilization of the solar energy as discussed later in this section.

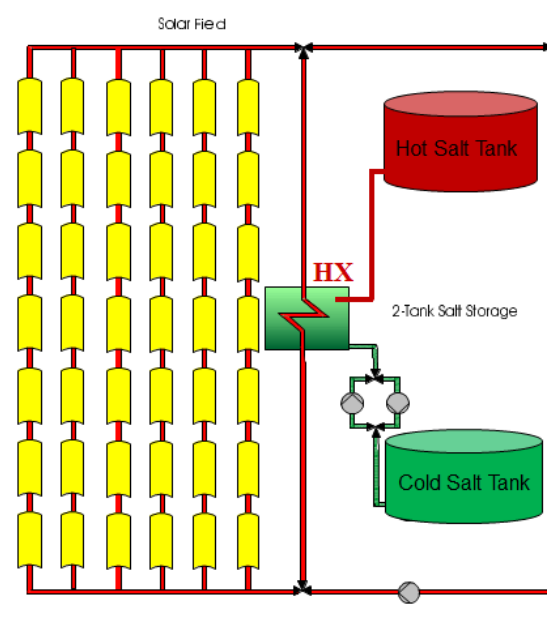

(a) Trough with indirect storage
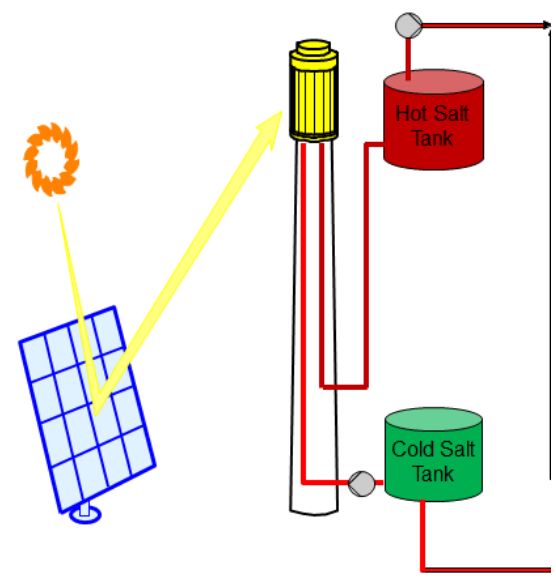

(b) Tower with direct storage

Figure 1. Configuration of a CSP+TES plant

The two primary benefits of employing TES with CSP are increased dispatchability (including capacity credit) and reduced cost of energy because of increased utilization of the power block (capacity factor). The benefits of dispatchability are as follows. Energy stored in a very efficiency medium can be used during periods of peak demand (and prices), and it can allow a plant to displace conventional generation equipment. The benefit of increased capacity factor is associated with the greater amount of energy that can be collected and generated by the power block. Power blocks are typically one of the more expensive parts of a CSP+TES system; by operating the power block during more hours of the day its upfront costs can be distributed over more units of energy. 
The solar multiple (SM) is a key concept in defining the configuration and performance of a CSP+TES plant. A related term, sometimes referred to as inverter loading ratio (ILR) is applied to PV+ESS plants; it is discussed later in this section. The SM is a measure of the relative size of the solar field and power block. The SM normalizes the size of the solar field in terms of the power block size. For additional discussion of SM, see Jorgenson et al. (2013) and Izquierdo et al. (2010). A solar field with an SM of 1.0 is of sufficient size to provide energy to operate the power block at its rated capacity under reference conditions. The collector area of a solar field with a higher or lower SM will be scaled based on the solar field with a multiple of one (i.e., a field with a SM of 2.0 will cover roughly twice the collector area of a field with a SM of 1.0). A $\mathrm{SM}$ of 2.0 or greater is common in plants with storage, and the solar field with this SM will deliver twice the energy that can actually be used by the power block under reference conditions, meaning excess energy must be stored or dumped.

Figure 2 depicts the energy flow a CSP plant with a power block rating of 300 megawatts (MW) and a SM of 2.0 over three days. Because of the solar multiple, the solar field collects as much as $600 \mathrm{MW}$ (electrical equivalent) energy. Any electrical energy delivered from the solar field that exceeds the maximum thermal rating of the power block rating must be stored or dumped (if the storage capacity is full). In such simplified dispatch, the plant stores energy and uses it during periods of passing clouds or after sunset. In reality, the plant would often be dispatched differently depending on grid conditions. Because of the combination of both the SM of 2.0 and storage, the capacity factor of the plant (measured by power block rating) is roughly doubled compared to a plant with an SM of 1.0 and no storage.

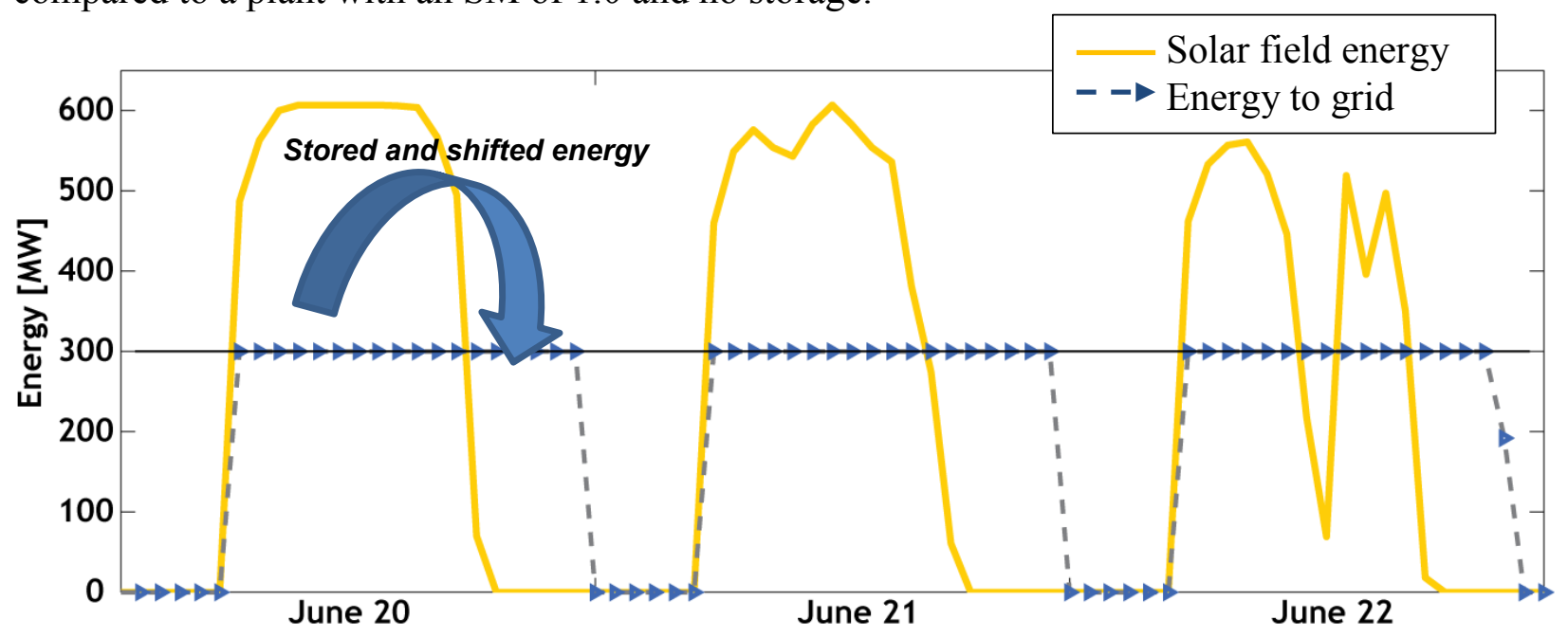

Figure 2. Impact of the SM on the energy flow of a CSP plant

Increasing the SM of a CSP plant will increase its capacity factor and will generally decrease the LCOE due to increased utilization of the power block. Figure 3 shows the impact of SM on capacity factor and LCOE. The results were generated using NREL's System Advisor Model (SAM) Version 2016.3.14. The SAM Generic System Model was used to estimate CSP+TES tower capital cost and performance based on the U.S. Department of Energy SunShot Initiative projections for a power tower located in Daggett, California. We model a low-cost solar field integrated with thermal energy storage and a supercritical carbon dioxide (sCO2) power block. The model shows a general trending in reduced LCOE associated with higher capacity factors 
due to both increased SM and increased storage. We see that at low SMs the minimum LCOE is achieved with a few hours of storage, and as SM increases, the optimal hours of storage also increases.

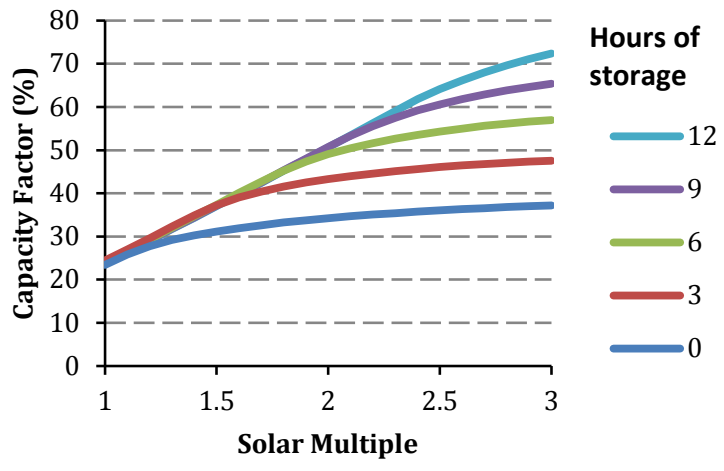

(a) Capacity Factor

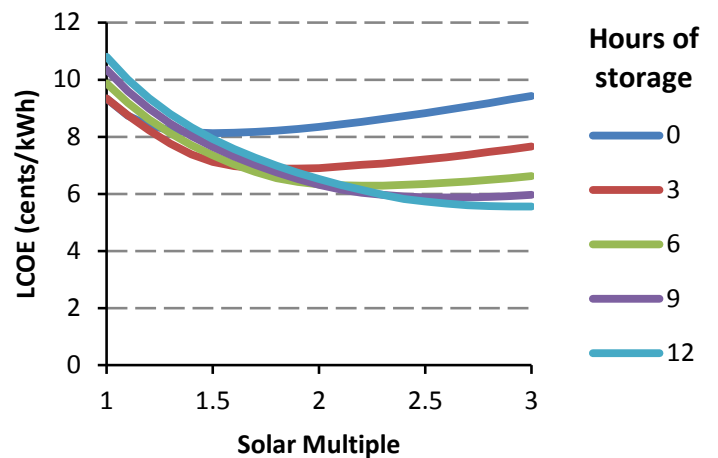

(b) LCOE

Figure 3. Relationship between SM and capacity factor/LCOE

Figure 3 also shows a wide range of capacity factors is possible, ranging from peaking $(<25 \%)$ to near baseload (over $70 \%$ ) output.

As opposed to CSP+TES, neither the configuration of a PV+ESS plant nor its capacity factor is well defined. Unlike with CSP+TES, there have been no large-scale deployments of PV+ESS systems designed to provide dispatchable energy to establish nomenclature or technical performance characteristics.

Figure 4 illustrates a possible configuration of a PV+ESS system. In this case, the capacity factor would be defined relative to the inverter AC rating, which is similar to the power block of a $\mathrm{CSP}+\mathrm{TES}$ plant. The advantage of this configuration, as with that of CSP+TES is the ability to decrease the cost of some of the power components.

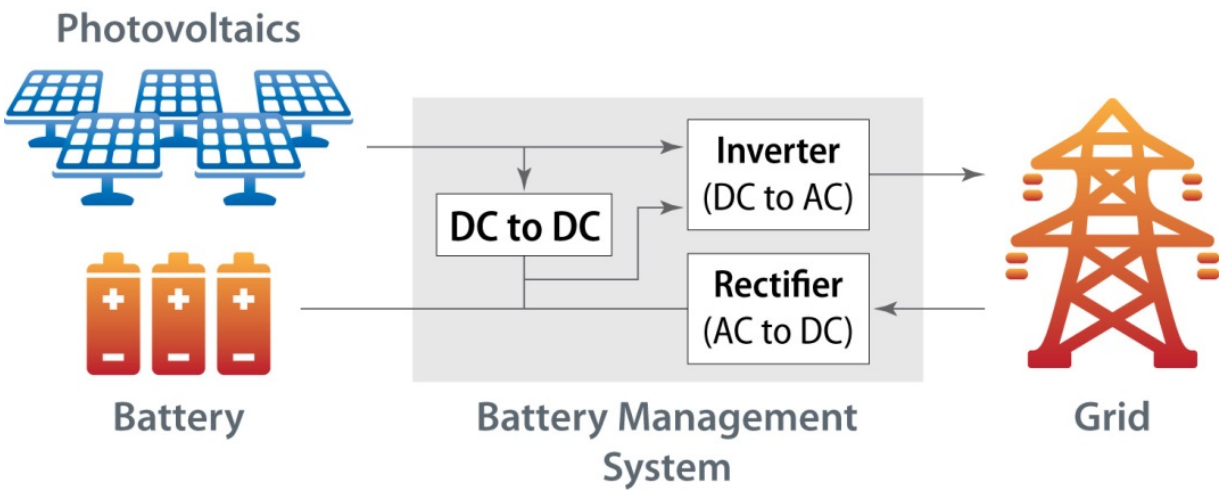

Figure 4. PV+ESS system components 
As with CSP, adding coupled storage can produce a dispatchable resource. And, by increasing the amount of PV modules relative to a fixed amount of inverter capacity, the plant can increase its capacity factor, based on the inverter rating. The direct analog to SM is the ILR, or DC/AC ratio, which measures the ratio of the $\mathrm{PV}$ modules to the inverter $\mathrm{AC}$ rating. By increasing the ILR, a greater amount of energy is collected, and sent either to the grid or to storage. Figure 5 provides the capacity factor of a PV+ESS system with different ILRs and amounts of storage. Of note in this figure is the increase in capacity factor that results from systems with an ILR $>1.0$ even without storage. This is due to the fact that with an ILR $=1.0$ the system rarely produces full output, and additional losses means that a DC/AC ratio of 1.2 to 1.3 can be (and often is) deployed without significant curtailment even without storage.

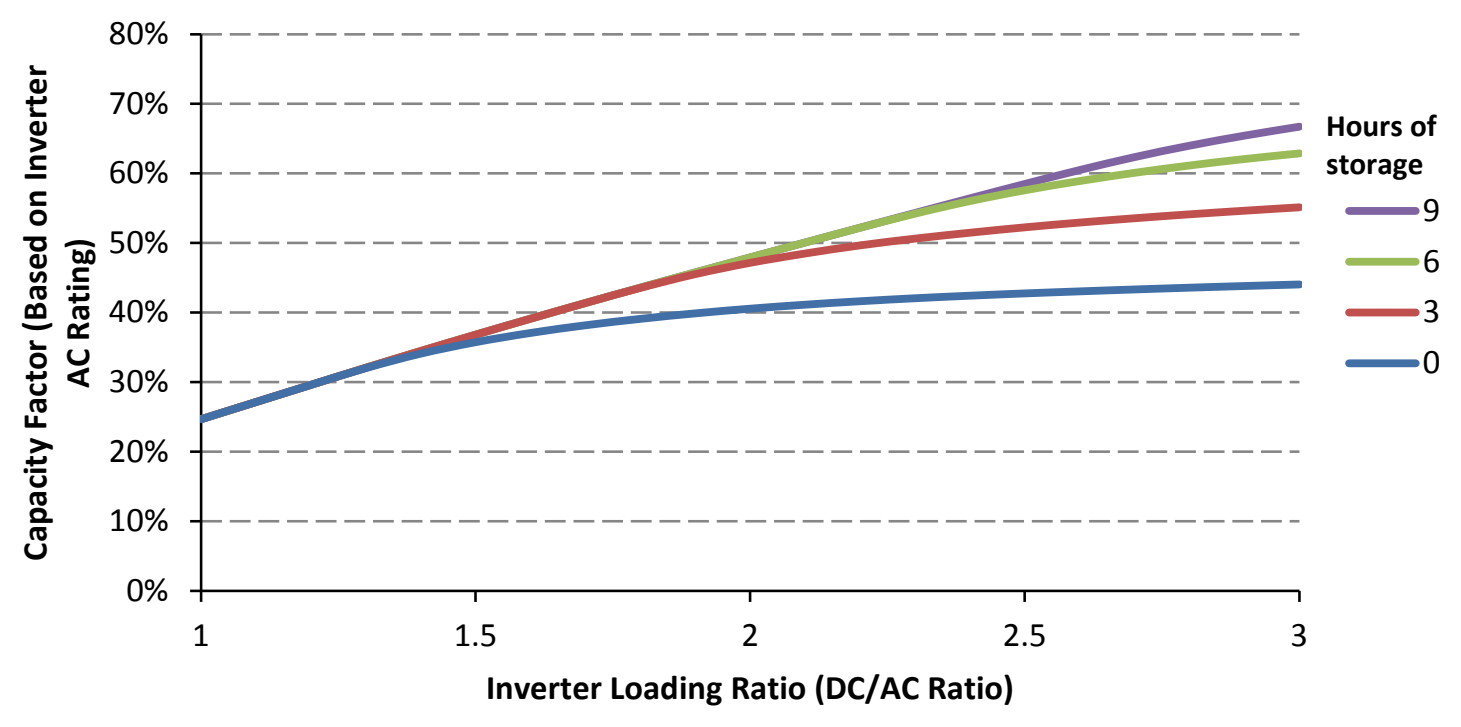

Figure 5. Relationship between capacity factor and inverter loading ratio with different amounts of
storage for a PV/battery system

The use and sizing of the storage system components varies between the generation types and configurations. For CSP, we assume direct storage, meaning the storage system can potentially store all incoming solar energy. For PV, we assume the battery power capacity is set equal to the inverter rating. This means that during periods of high solar output (where the PV generation is greater than the inverter rating), the system can store only a fraction of the solar energy, so the energy produced must either go to the grid or be curtailed. Curtailment only occurs in the extreme case, with very high ILRs (greater than about 2.4), when the solar output (after losses) exceeds the combined capacity of the inverter and battery. Table 1 summarizes the various modes the PV+ESS system can operate under, assuming an inverter rating of $100 \mathrm{MW}_{\mathrm{AC}}$ and highlights some of the constraints that a PV+ESS system experiences, which potentially reduces its value compared to a system where storage is deployed independently of solar. 
Table 1. Energy Flow of 100-MW AC PV+ESS System with Differing Levels of PV System Production

\begin{tabular}{lllll}
\hline $\begin{array}{l}\text { Output of PV } \\
\text { System (AC } \\
\text { Equivalent MW) }\end{array}$ & $\begin{array}{l}\text { From PV } \\
\text { to Grid }\end{array}$ & From PV to Storage & $\begin{array}{l}\text { From } \\
\text { Storage } \\
\text { to Grid }\end{array}$ & $\begin{array}{l}\text { From Grid } \\
\text { to Storage }\end{array}$ \\
\hline$<100$ & $\begin{array}{l}\text { Up to } \\
\text { current PV } \\
\text { output }\end{array}$ & $\begin{array}{l}\text { Up to current PV output } \\
\text { (current PV output minus PV } \\
\text { energy sent to grid) }\end{array}$ & $\begin{array}{l}\text { Up to } 100 \\
\text { minus PV } \\
\text { output }\end{array}$ & $\begin{array}{l}\text { Up to } 100 \\
\text { minus PV } \\
\text { output }\end{array}$ \\
$>100<200$ & Up to 100 & $\begin{array}{l}\text { Up to } 100 \text { (100 minus PV } \\
\text { energy sent to grid) }\end{array}$ & Zero & Zero \\
$>200$ & Up to 100 & $\begin{array}{l}\text { Up to 100; excess generation } \\
\text { (when PV output exceeds } \\
\sim 230) \text { will be curtailed }\end{array}$ & Zero & Zero \\
\hline
\end{tabular}

The data in the table assumes the capacity of the inverter and the battery are equal.

For this study, we establish three base solar-plus-storage configurations with a range of intermediate load capacity factors of approximately $40 \%, 50 \%$, and $60 \%$ for a location in Daggett, California. Table 2 summarizes the characteristics of the various plant configurations and assumptions. ${ }^{1}$

Table 2. Summary of System Configuration Assumptions

\begin{tabular}{lll}
\hline & $\begin{array}{l}\text { CSP } \\
\text { (low/medium/high) }\end{array}$ & $\begin{array}{l}\text { PV+ESS } \\
\text { (low/medium/high) }\end{array}$ \\
\hline Generator power capacity & $100 \mathrm{MWac}$ & $100 \mathrm{MWac}$ \\
\hline SM (CSP) / ILR (PV) & $1.5 / 2.0 / 2.5$ & $1.5 / 2.1 / 2.6$ \\
\hline Hours of storage (usable) & $3 / 6 / 9$ & $3 / 6 / 9$ \\
\hline Capacity factor & $37.2 / 49.1 / 61.2^{\mathrm{a}}$ & $36.8 / 50.1 / 60.5^{\mathrm{b}}$ \\
\hline Storage input power capacity & Full output of solar field & $100 \mathrm{MWac}$ \\
\hline Storage efficiency & $(150 \mathrm{MWac} / 200 \mathrm{MWac} / 250 \mathrm{MWac})$ & \\
\hline Storage power capacity & $99 \%$ & $82 \%$ DC in to AC out \\
\hline Ratio of usable storage & Full output of solar field & 100 megawatts equivalent \\
\hline a Mehos et al. 2016 & $100 \%$ & $72 \%$ (see Footnote 3) \\
b Capacity factors for PV are calculated based on peak inverter capacity, not module capacity.
\end{tabular}

\footnotetext{
${ }^{1}$ We chose Daggett, California because of its high direct normal insolation (DNI) levels. Concentrating solar applications can only effectively focus DNI to create energy and therefore are economically limited to locations with high DNI levels. Solar technologies that do not concentrate sunlight, such as most PV applications, can use both the direct and diffuse components of solar radiation and can be economically deployed over a wider range of locations and conditions than concentrating technologies that depend on high DNI. Therefore, while this analysis applies to high DNI locations, in many parts of the United States, CSP will likely not be considered.
} 
We do not attempt to optimally dispatch the storage system, and we assume any energy generated by the PV system that exceeds the inverter rating is put into a battery and then released when the PV system is not generating at full output. The efficiency of the battery is assumed to be $80 \%$ on an AC-AC basis. However, we assume a slightly higher round trip efficiency in this scenario, assuming a slightly higher conversion efficiency using DC-DC conversion while charging. ${ }^{2}$ We also assume the battery is operated at a depth of discharge (DoD) of $80 \%$ to protect the life of the batteries. This means the actual energy capacity of the battery is $25 \%$ higher than indicated in Table 1 . We also assume that the battery's lifetime will be either 10 years or 15 years with a state of health of $80 \%$ capacity at the point of replacement (i.e., $20 \%$ degradation $)^{3}$; thus, these batteries must be replaced twice or once respectively, over the 30 -year analysis period.

\footnotetext{
${ }^{2}$ While it has been reported that some battery cells have achieved a $90 \%$ roundtrip efficiency, an energy storage system would produce further losses beyond the battery cells; many energy storage systems may now be operating at a roundtrip efficiency lower than $80 \%$. While this is likely to improve by 2030 , we kept the roundtrip efficiency at $80 \%$ in this analysis to be conservative.

${ }^{3}$ Due to the degradation of battery capacity, we modeled the need to oversize battery capacity by the average level of undercapacity over the life of the battery, or $10 \%$ (i.e., $20 \%$ degradation rate over the battery's lifetime divided in half). Therefore, battery system costs are increased by $1 /(1-10 \%)-1$, or $11 \%$, to compensate for battery degradation, and $1 /(1-20 \%)-1$, or by $25 \%$ to compensate for limiting the depth of discharge.
} 


\section{Technology Pricing Trends}

We use two approaches to estimate future technology costs: (1) the historical experience curves for PV, CSP, and batteries, and (2) aggregated analysts' projections of technology costs. A technology's progress rate is defined as the average price decrease following each doubling of cumulative production. The concept behind an experience curve is that some learning occurs within an industry with each unit produced, allowing for less-expensive production methods with the next unit of that technology. While experience curves merely represent historical averages, many technologies have realized steady rates of progress over relatively long periods. That said, many factors can influence a particular technology's experience rate, which may cause the rate of cost reduction to deviate from the historical trend. For example, the experience curve aggregates multiple factors that can contribute to reduction in the marginal cost of production, including changes in production, changes in the product itself, and changes in input prices. Thus, experience curves aggregate gains realized through factors such as R\&D advances, economies of scale (in manufacturing and procurement), and sharing of information and experience across technologies and locations.

One of the challenges of using experience curves for projecting cost reductions is related to defining boundaries for the product being modeled, and for the geographic zone of production being considered. Here, we disaggregate the PV+ESS into four discrete "products:" the PV module, the PV balance of system (BOS), the battery cell, and the battery BOS. We model CSP experience as a single product CSP plant.

The degree to which a particular technology will fall in price in the future, if it follows past experience rates, depends on how much is deployed in the marketplace. For this reason, we also aggregate analysts' projections of technology deployment over time in order to compare CSP and PV on the same time-scale. For a given experience rate, a more aggressive deployment rate results in less time needed to achieve a technology's cost decline.

\subsection{PV System Cost Trends: Experience Curve}

Since 1976, the global average price of PV modules has fallen $21 \%$ for every doubling of cumulative shipments. As shown in Figure 6, during periods of undersupply (e.g., 2008) or oversupply (e.g., 2012), prices have deviated above or below the historical experience curve trend line, but they have generally trended back toward the curve over time. To project PV module price, we fit a power-curve trend line to the historical data as shown in the figure $(y=$ $\left.57.881 \times x^{-0.338}\right)$, and we use this equation to calculate future PV module pricing $(\mathrm{y})$, based on projected cumulative global shipments $(\mathrm{x})$. 


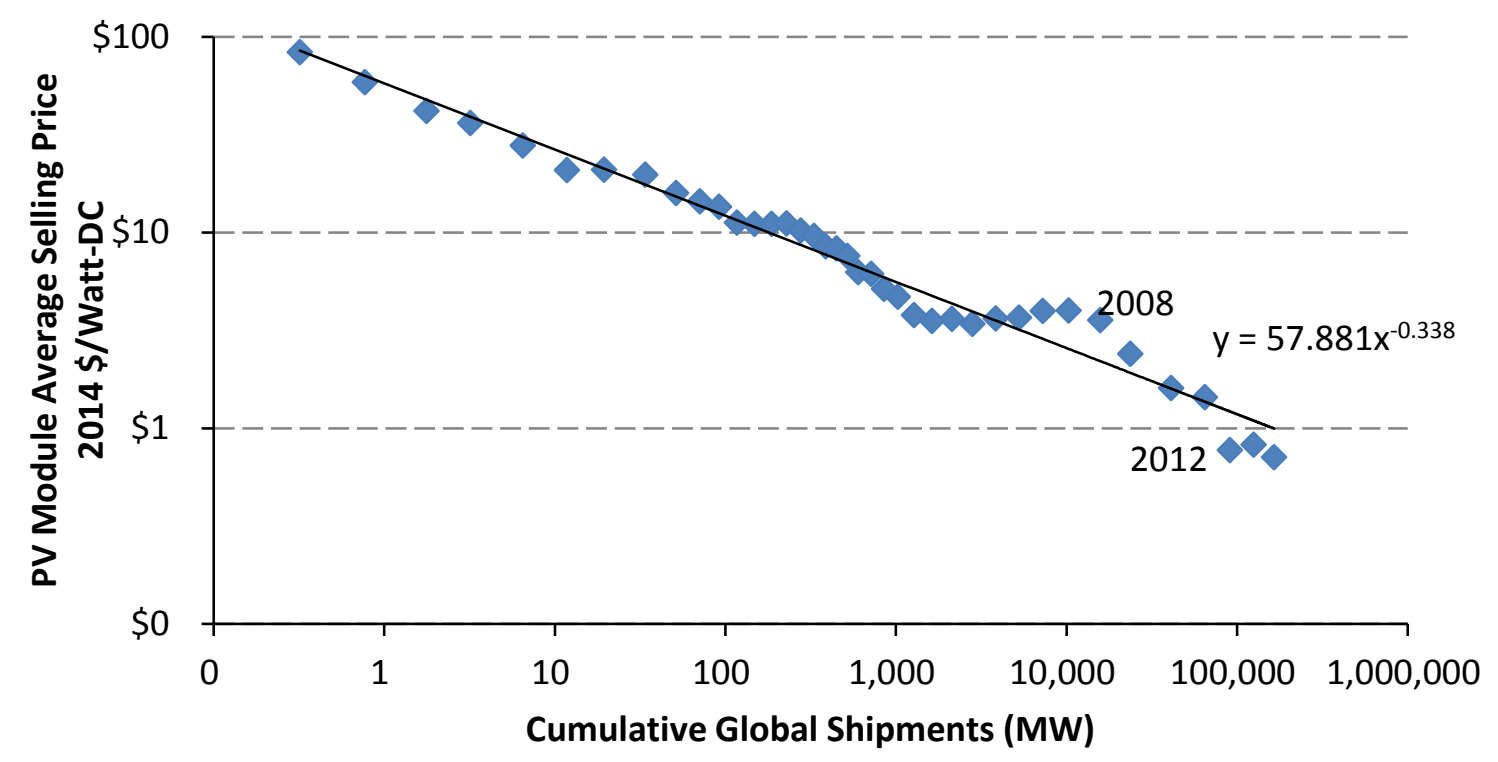

Figure 6. Experience curve for PV modules, 1976-2014

Source: Mints 2015

We collected global shipment projections from three sources (Figure 7). As illustrated in the figure, cumulative global PV module shipments are projected to be between about 0.5 terawatts (TW) and 3.7 TW by 2030, which represents dramatically different visions of the role of PV in the global energy system.

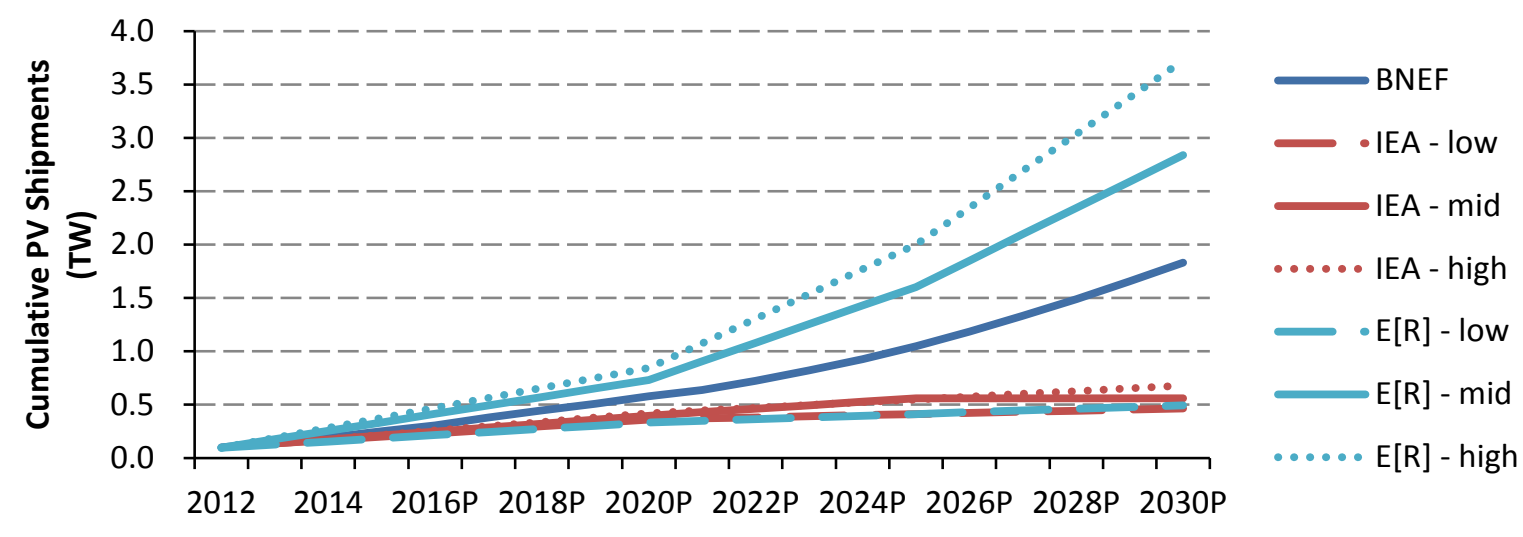

Figure 7. Projected cumulative global PV module shipments, 2012-2030

Sources: BNEF 2016; IEA (2015); Teske et al. 2015

$\mathrm{IEA}=$ International Energy Agency

We then use the high, median, and low deployment cases to estimate PV module prices based on the historical experience rate of $21 \%$. As a result, 2030 global PV module prices are projected to 
decline to $\$ 0.35 / \mathrm{W}, \$ 0.62 / \mathrm{W}$, and $\$ 0.70 / \mathrm{W}$ (in 2014 dollars) for the low, middle, and high cases respectively, as shown in Figure 8.

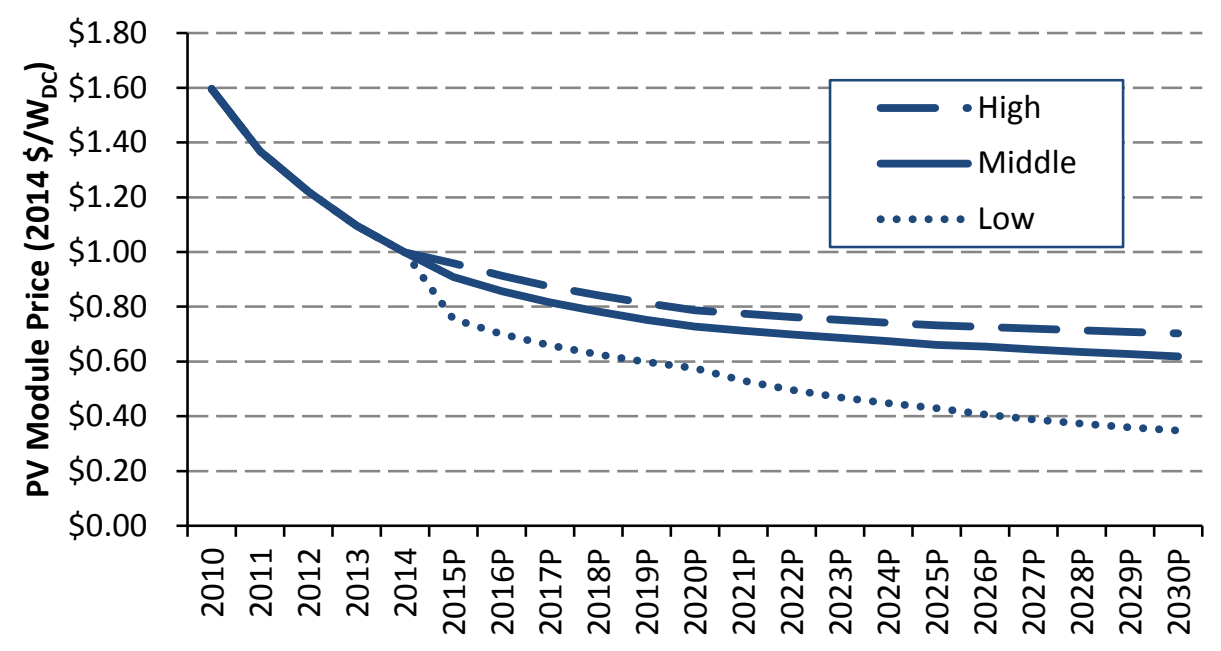

Figure 8. Projected PV module price using historical experience curve, 2010-2030

Current module pricing is below the historical experience curve, and because we are using the historical trend line for our projections, the low and middle projected values for 2030 are very close to the level of current global module sales prices. In other words, in these two cases, we have very conservative projections of PV module prices. The degree to which historical module efficiency gains have impacted module production costs would be reflected in the experience curve; however, module efficiency improvement also significantly impact system price on a perwatt basis as well. Therefore, even if module price is not decreasing, modules can still significantly lower the overall system price through efficiency gains.

Despite PV module price differences between markets, standard efficiency PV modules represent the bulk of the market and are in many ways global commodities, thus, we model PV module pricing at the global level. However, PV BOS costs are very much location-specific with local "learning by doing," labor costs and practices, and regulations driving much of the PV BOS costs. For this reason, we analyze the experience rate for U.S. utility-scale PV BOS over time, as show in Figure 9. 


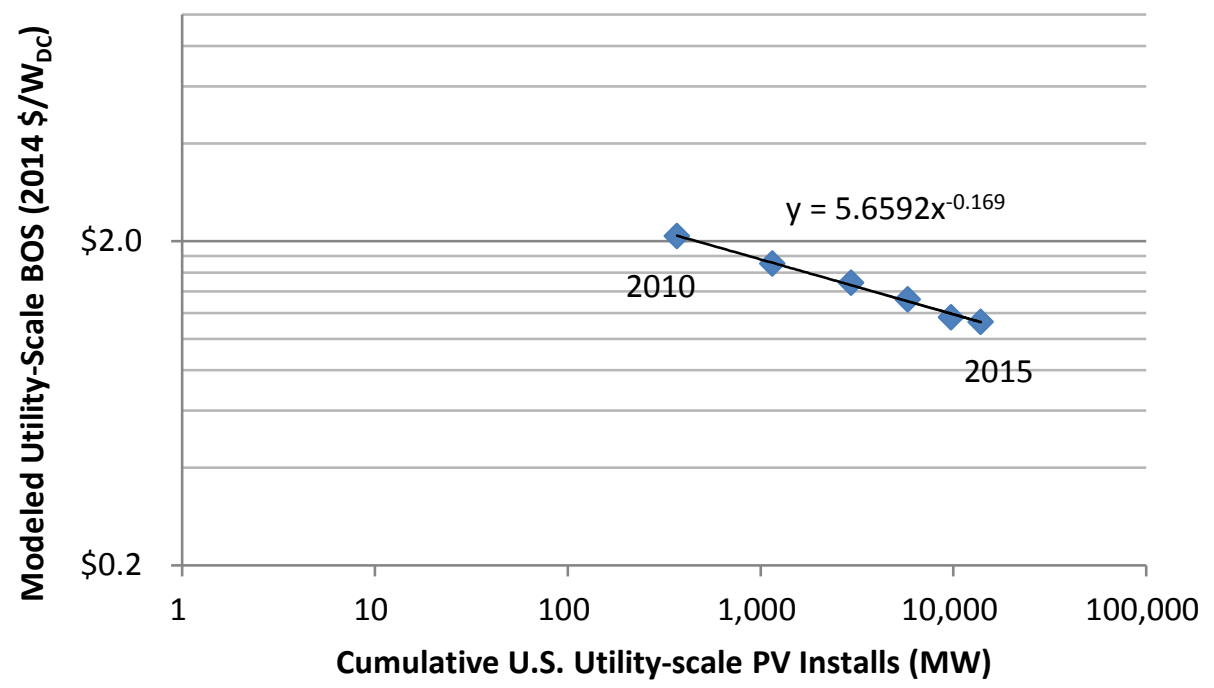

Figure 9. Experience curve for U.S. utility-scale PV BOS, 2010-2015

Sources: Chung et al. 2015; Feldman et al. 2015; SEIA and GTM Research 2015

Figure 9 illustrates that U.S. utility-scale BOS costs declined, on average, 11\% for every doubling of cumulative installs from 2010 to 2015. This falls within the range of power technologies' progress ratios as reviewed by Rubin et al. (2015). Again, in order to project U.S. utility-scale PV BOS pricing, we fit a power-curve trend line to the historical data as shown in the figure $\left(y=5.6592 \times x^{-0.169}\right)$, and we use this equation to calculate future U.S. PV BOS pricing (y), based on projected cumulative U.S. utility-scale PV installs (x).

We collected U.S. utility-scale PV projections from five sources (Figure 10). For the analysts' projections that did not project through 2030, a 5\% escalator, per year, was assumed after the last projected year given in the analysis. A growth rate of 5\% is considerably less than the average growth rates for these projections, and it was chosen to be conservative in extending these projections. It should also be noted that some of these projections included neither the five-year extension to the federal investment tax credit (ITC) passed in late 2015 nor the adoption of the Clean Power Plan, which would likely push installations higher than previously projected. Based on these assumptions, 2030 U.S. utility-scale PV system BOS prices are projected to decline to $\$ 0.83 / \mathrm{W}, \$ 0.87 / \mathrm{W}$, and $\$ 1.07 / \mathrm{W}$ for the low, middle, and high cases respectively. 


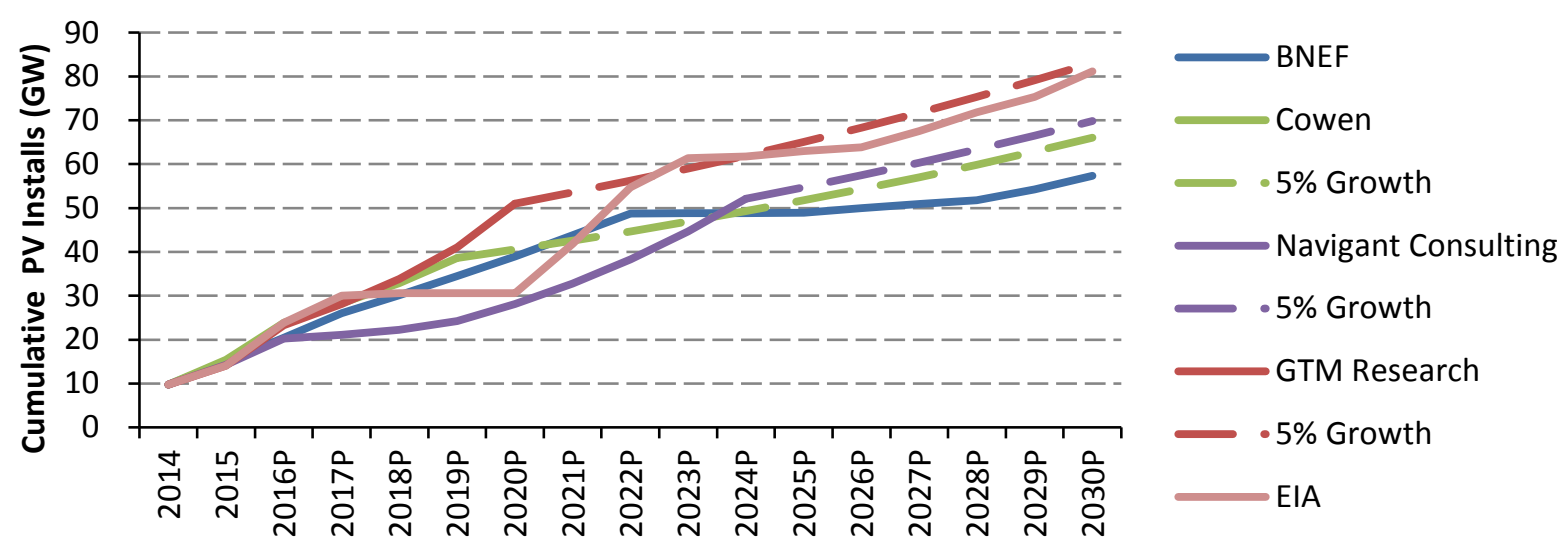

Figure 10. Projected U.S. utility-scale PV deployment, 2014-2030

Sources: BNEF 2016; EIA 2016; Osborne, Boyes, and Sutton; 2015; Rodriguez Labastida and Gauntlett 2015; SEIA and GTM Research 2015

\subsection{PV System Cost Trends: Analysts' Projections}

To provide a counterpoint to the experience curve approach, we draw on a set of analysts' projections of U.S. utility-scale PV system pricing through 2030, as presented in NREL's Annual Technology Baseline (ATB) (Cole et al. 2016). As shown in Figure 11, the ATB uses a widerange of sources to develop a set of high, medium, and low PV system price projections. ${ }^{4}$

\footnotetext{
${ }^{4}$ Numbers in this draft represent preliminary numbers and will be updated with final ATB numbers when available.
} 


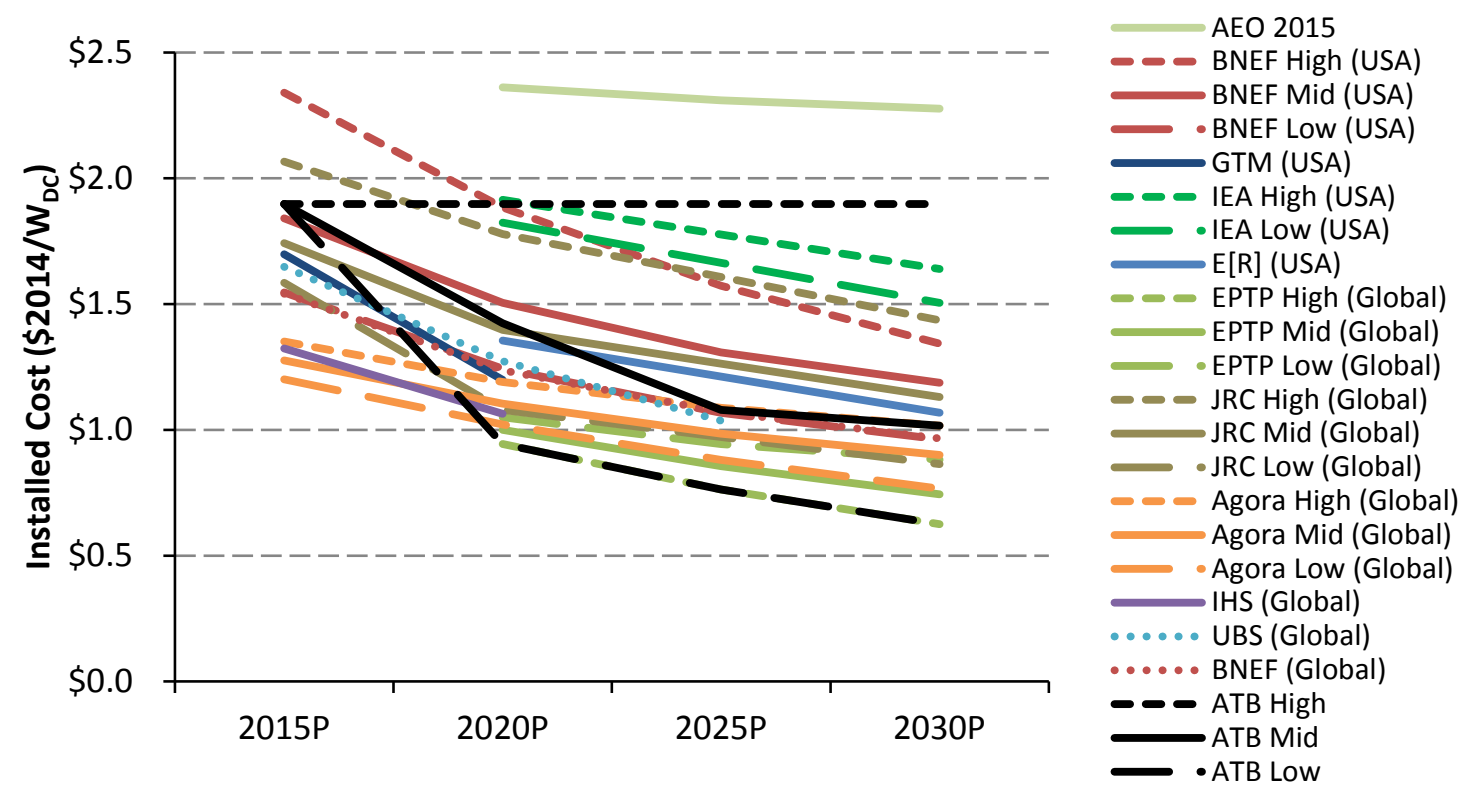

Figure 11. Projected U.S. utility-scale system prices, 2015-2030

Sources: BNEF 2015a; Chase 2015; Cole et al. 2016; EIA 2015; Fraunhofer ISE 2015; Gandolfi et al. 2015; IEA 2015; JRC 2014; Sharma 2015; Shiao 2015; Teske et al. 2015; Vartiainen, Masson, and Breyer 2015

\section{AEO $=$ Annual Energy Outlook, BNEF = Bloomberg New Energy Finance, EPTP $=$ European PV Technology Platform, JRC = Joint Research Centre}

Projections of utility-scale PV plant system costs are based on a collection of 20 system price projections from 10 separate institutions. To adjust all projections to the ATB's assumption of single-axis tracking systems, $\$ 0.15 / \mathrm{W}$ was added to all price projections that assumed fix-tilt technology, and $\$ 0.075 / \mathrm{W}$ was added for all price projections that did not list whether the technology was fixed-tilt or single-axis tracking. The "high" case assumes that system pricing remains at current levels. The "low" case represents the minimum estimate in the data set. The "mid" case represents the median estimate in the data set. However, the values before 2025 include a price adder that represents the difference between the median U.S. price estimate and the median price estimate for the entire data set. This adder decreases on a straight-line basis between 2015 and 2025. It is assumed after 2025 that U.S. prices will be on par with global averages. To account for the temporal variation in price projections, the "mid" and "low" cases make estimates every five years through 2030, with a straight-line change between estimates. 


\subsection{PV System Price: Comparison of Results Using Different Methodologies}

As shown in Figure 12, between the experience-curve based projections and analysts-based projections, we capture a wide range of potential futures - from PV prices stagnating to $\mathrm{PV}$ dropping by roughly $75 \%$ between 2015 and 2030 . We find that the experience curve methodology produces projections that are significantly higher than analysts' projections, in particular for the mid and low cost cases. Based on these results, one could argue that most analysts believe the industry will progress faster than the historical average experience rates.

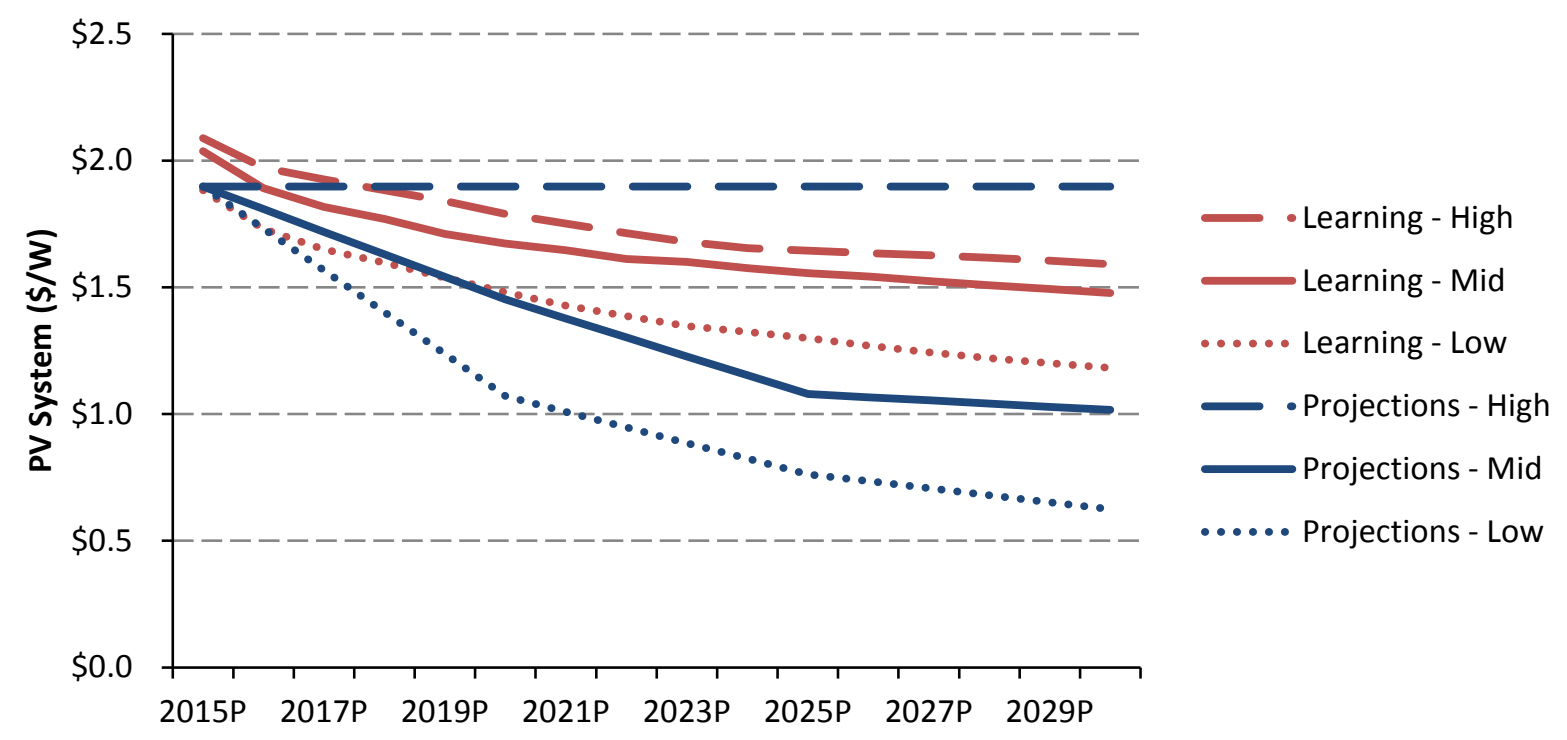

Figure 12. Projected utility-scale PV system prices from historical experience curves and analyst estimates, 2015-2030

\subsection{Battery Cost Trends: Experience Curve}

While lithium-ion (Li-ion) batteries are currently not the dominant technology used for gridbased energy storage, many analysts view them as having the greatest potential for cost reduction and future deployment. Here we draw on recent analysis of Li-ion batteries to set a benchmark that other technologies would need to meet to be competitive. For example, Nykvist and Nilson (2015) collected and analyzed historic, current, and projected costs of Li-ion battery packs used in battery electric vehicles (BEV); their costs are summarized in Figure 13. While Nykvist and Nilson examine the cost reduction potential of Li-ion battery technology for electric vehicles (versus the electric power sector), their analysis provides important insights for the potential use of Li-ion batteries in other sectors. As the cost of Li-ion batteries decline, they will be commoditized, and we assume that as the electric vehicle industry grows the electricity industry will be able to benefit from declining costs and growing production capacity. ${ }^{5}$ For this reason, we use cost and deployment projections for Li-ion batteries as a proxy for energy storage more

\footnotetext{
${ }^{5}$ Batteries used in utility-scale storage applications may be built differently than those used in smaller applications (e.g., residential solar and electric vehicles) to benefit from the larger storage size and thus may have lower costs. However, we conservatively assume the same battery pack price between applications because these projects will at least have access to the smaller-sized products.
} 
generally. This approach is a conservative one, as the Li-ion battery industry will benefit from growth in deployment in other sectors, including consumer electronics and the power sector.

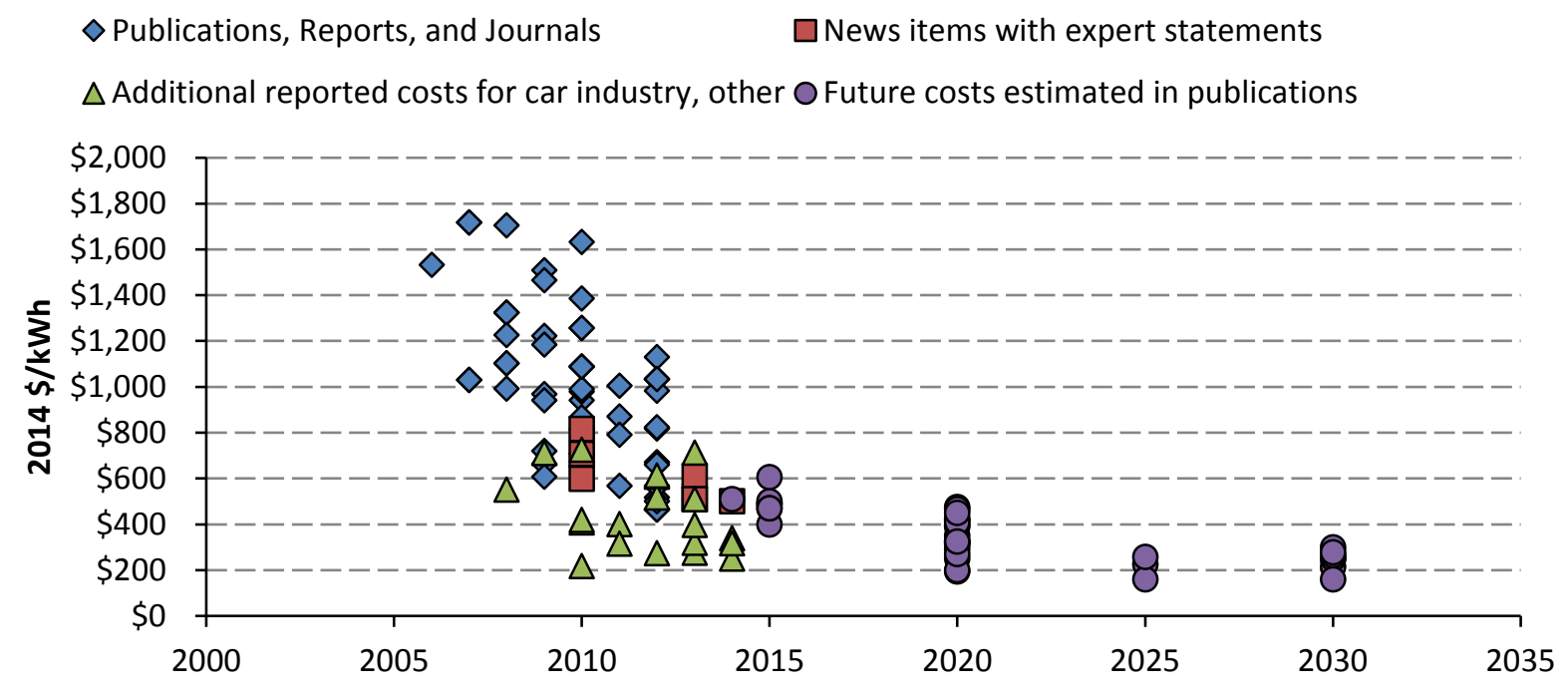

Figure 13. Cost of Li-ion battery packs

Source: Nykvist and Nilson 2015

Figure 13 illustrates that Li-ion batteries have realized an average cost decline of $14 \%$ per year, from 2007 to 2014 , and $8 \%$ for industry leaders, with a 2014 industry-average price of $\$ 410$ per kilowatt-hour $(\mathrm{kWh})$ and an average industry leader cost of $\$ 300 / \mathrm{kWh}$.

Nykvist and Nilsen (2015) also modeled the experience rate of Li-ion battery technology (Figure 14). They found a $6 \%$ experience rate for market leaders and an industry average experience rate of $9 \%$.

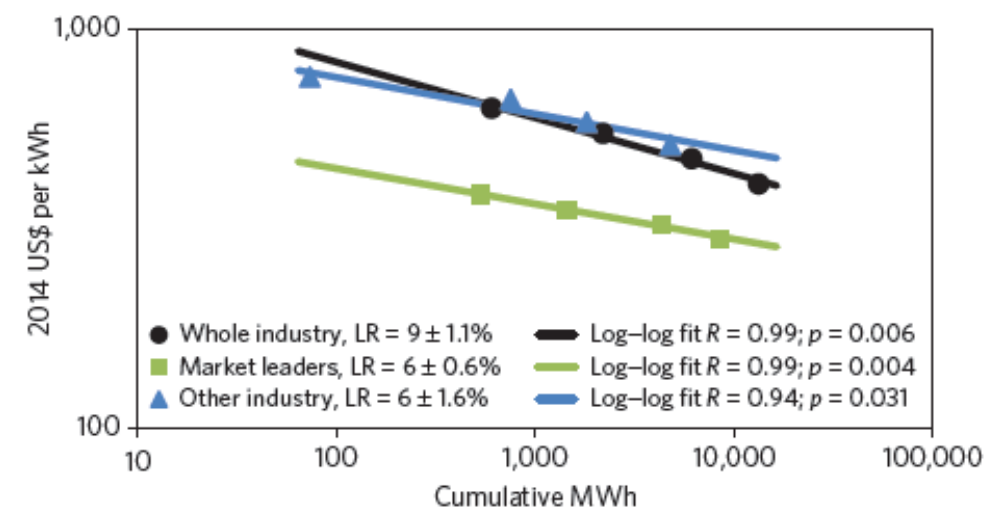

Figure 14. Modelled experience curves for battery packs

Source: Nykvist and Nilson 2015

"Other industry" represents the industry as a whole, with the market leaders subtracted.

$$
\mathrm{MWh}=\text { megawatt-hour }
$$


We use Nykvist and Nilson's industry average 2014 price of $\$ 410 / \mathrm{kWh}$ and their industry average experience rate of $9 \%$ to calculate projected battery costs. This experience rate aligns with the experience rate observed by Bloomberg New Energy Finance of 9.4\% for electric vehicle Li-on batteries, from 2010 to 2014 (BNEF 2015b). To calculate future battery pack pricing, we use the standard power curve formulation drawing on a range of global battery-pack deployment projections (Figure 15).

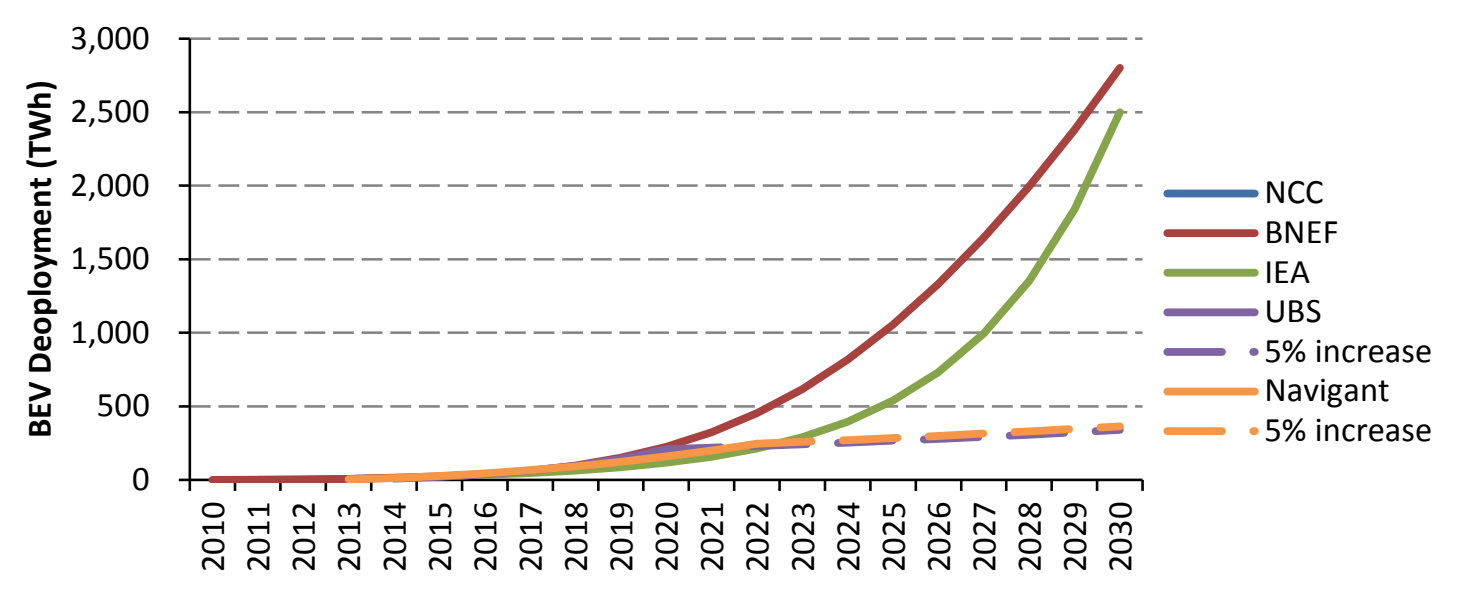

Figure 15. Projected battery-pack deployment, 2010-2030

Sources: Gandolfie et al. 2015; BNEF 2015b; IEA 2015; UNFCCC 2016; Navigant 2013; Nykvist and Nilson 2015

For analyst forecasts that only project car sales, this analysis assumes an average battery size for a car of $25 \mathrm{kWh}$.

Global BEV deployment projections were collected from various sources (Figure 15). All analysts' projections that do not project through 2030 assume a 5\% escalator, per year, after the last projected year; while 5\% is considerably less than the average growth rates for these projections, we chose 5\% to be conservative in our estimates. Based on these assumptions, 2030 L-ion battery pack prices are projected to decline to $\$ 202 / \mathrm{kWh}, \$ 217 / \mathrm{kWh}$, and $\$ 249 / \mathrm{kWh}$ for the low, middle, and high cases respectively.

While we model battery pack pricing at the global level, we model battery BOS at the national level. As with PV, battery BOS pricing is more location-specific due to the rapid scaling of the energy storage market, as well as the diversity of market uses; from back-up power for residential homes to large-scale grid storage, there is a large range in estimated BOS costs for batteries in the United States. This is in part due to the large range in assumed battery size (30 minutes to 10 hours of storage) over which BOS costs are spread; the larger the storage size the lower the BOS costs (on a per kWh basis). Analysts estimate 2015 battery BOS costs to be between $\$ 670 / \mathrm{kW}$ (GTM Research 2016) and \$942/kW (Roberts 2015).

A recent GTM Research report (2016) found that battery storage BOS costs followed an experience rate of about $18.8 \%$ for every doubling in cumulative capacity from 2012 to 2015 . We use the standard power curve formula to calculate future U.S. battery BOS costs based on estimated cumulative battery deployment (Figure 16). 


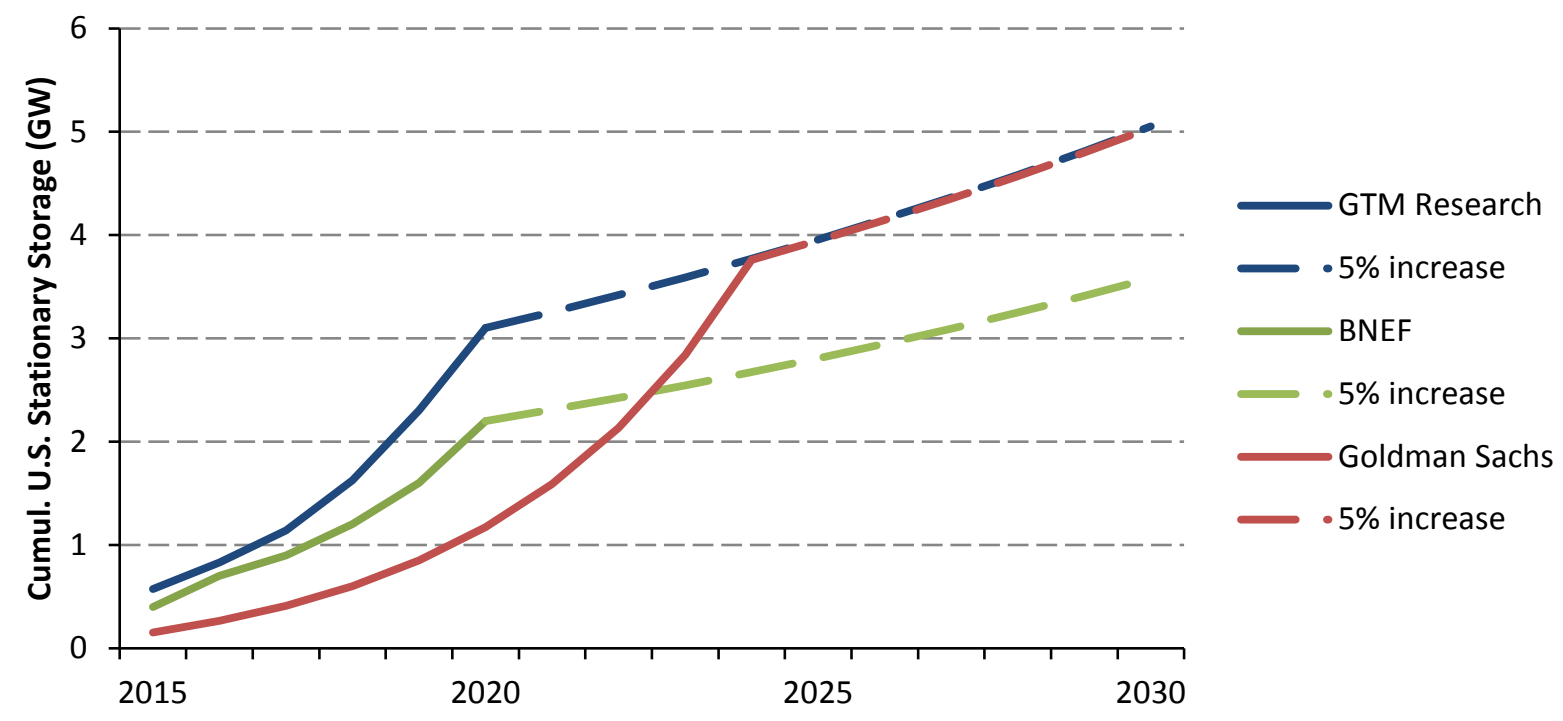

Figure 16. Projected U.S. stationary storage deployment, 2015-2030

Sources: BNEF 2014; GTM Research 2016; Lee et al. 2015

Does not include pumped storage

U.S. stationary storage deployment projections were collected from three sources (Figure 16). All analysts' projections that do not project through 2030 assume a 5\% escalator, per year, after the last projected year; while $5 \%$ is considerably less than the average growth rates for these projections, we chose $5 \%$ to be conservative in our estimates. Based on a 2015 battery BOS cost of $\$ 806 / \mathrm{kW}$ (median estimate) and the high, median, and low growth rates in Figure 16, 2030 battery BOS costs are projected to decline to $\$ 417 / \mathrm{kW}$ for the high case and $\$ 376 / \mathrm{kW}$ for the low and medium cases.

\subsection{Battery Cost Trends: Analysts' Projections}

Figure 17 summarizes analysts' projections of U.S. Li-ion cell pricing through 2030. Their projections of future Li-ion cell costs are based on a collection of 28 battery pack cost projections. For modeling purposes, we calculate the maximum, median, and minimum projection every five years, with a straight-line change between estimates. Based on these projections, 2030 Li-ion battery pack prices are projected to decline to $\$ 100 / \mathrm{kWh}, \$ 210 / \mathrm{kWh}$, and $\$ 300 / \mathrm{kWh}$ for the low, middle, and high cases respectively. 


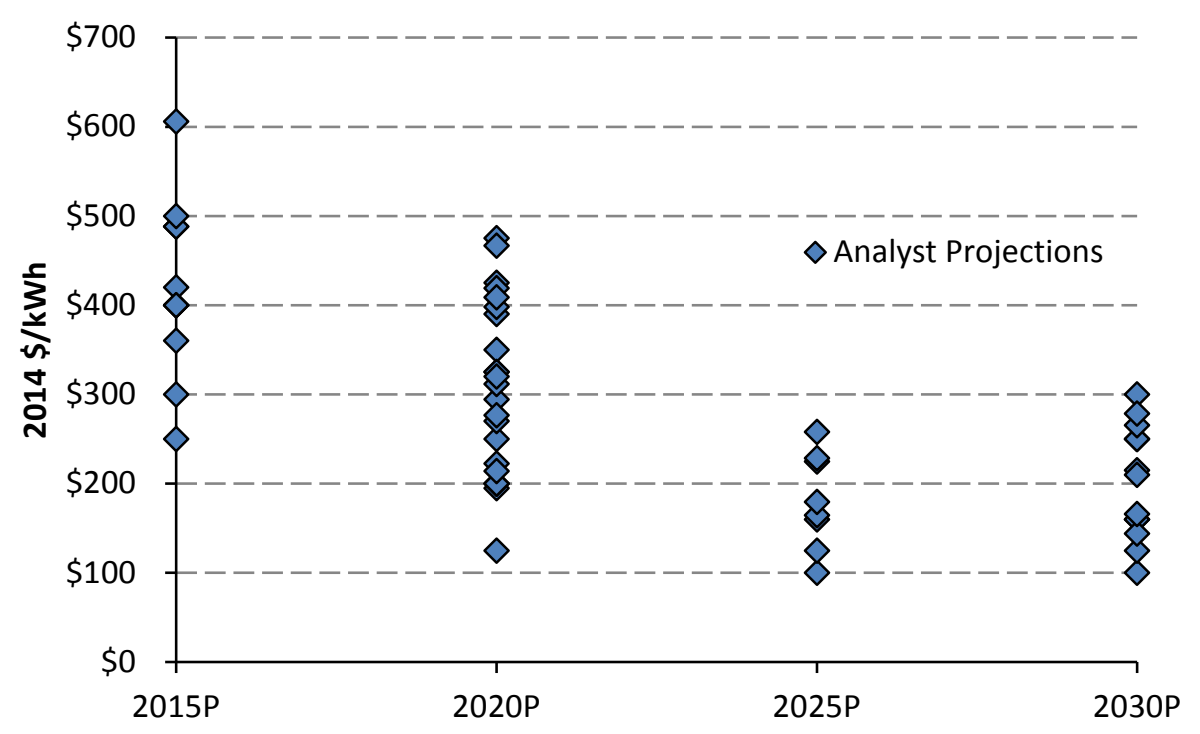

Figure 17. Price estimates for Li-ion battery pack, 2015-2030

Sources: BNEF 2015b; Gandolfi et al. 2015; Lee et al. 2015; Nykvist and Nilson 2015

We collected two data sets of future U.S. battery BOS costs, as summarized in Figure 18. Based on these, analysts' 2015 battery BOS costs are estimated to be between $\$ 670 / \mathrm{kW}$ and $\$ 942 / \mathrm{kW}$, and to decline to between $\$ 200 / \mathrm{kW}$ and $\$ 400 / \mathrm{kW}$ by 2030 , as illustrated in Figure 18 .

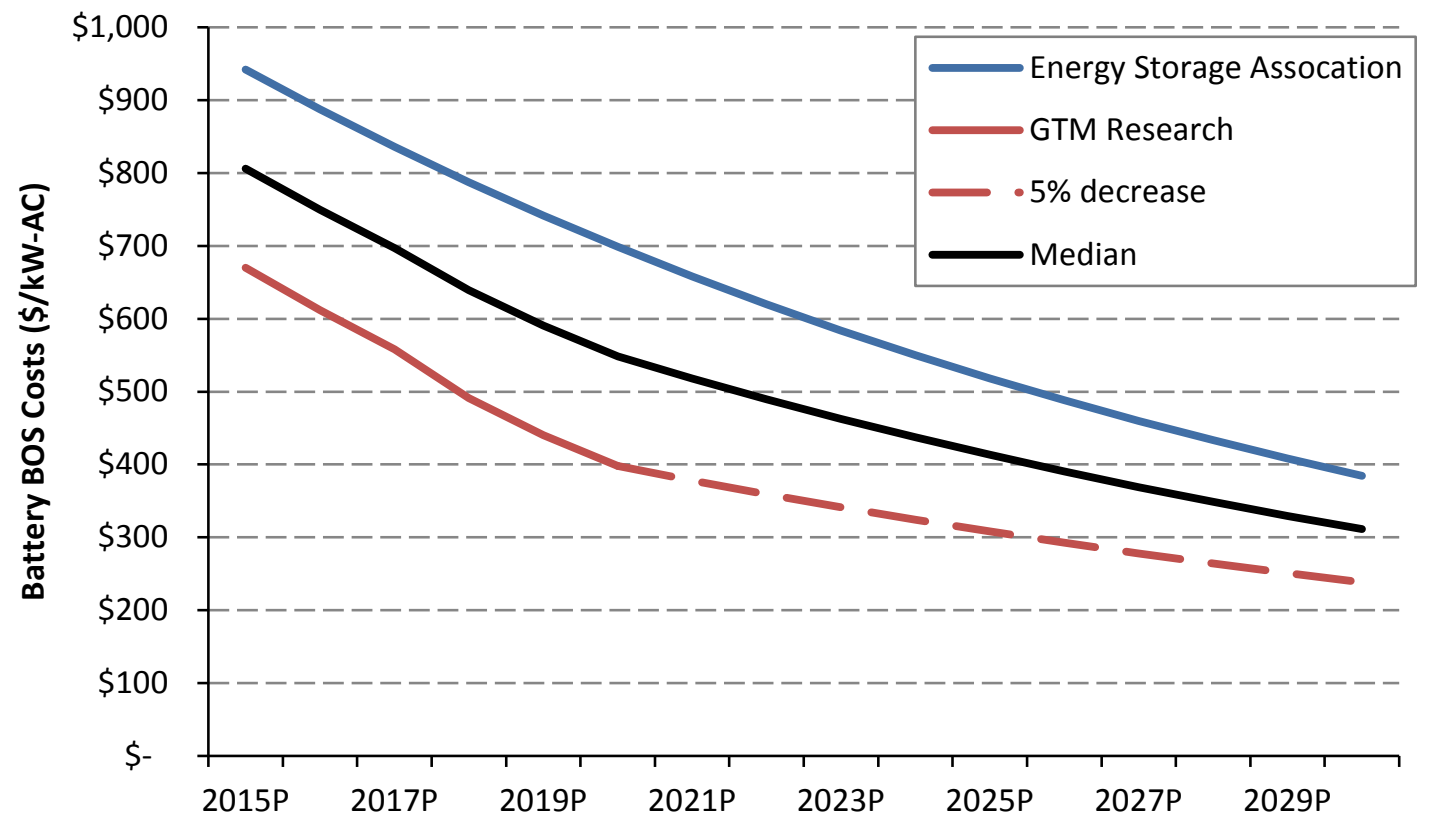

Figure 18. Estimated battery BOS costs, 2015-2030

Sources: GTM Research 2016; Roberts 2015

The GTM projection only goes to 2020 ; thus, we extend their projection to 2030 , assuming a $5 \%$ annual decrease in cost between 2020 and 2030. This rate of decline was set considerably slower than historical rate in order to be conservative. 


\subsection{Battery System Price: Comparison of Results Using Different Methodologies}

Combining battery pack and BOS price projections enables us to calculate projected battery system prices (Figure 19). Here we see that the mid-case U.S. battery system price projections in 2030 are similar for the two approaches. ${ }^{6}$ However, the experience curve approach produces a narrower range between the high and low cases than the analyst projection approach.

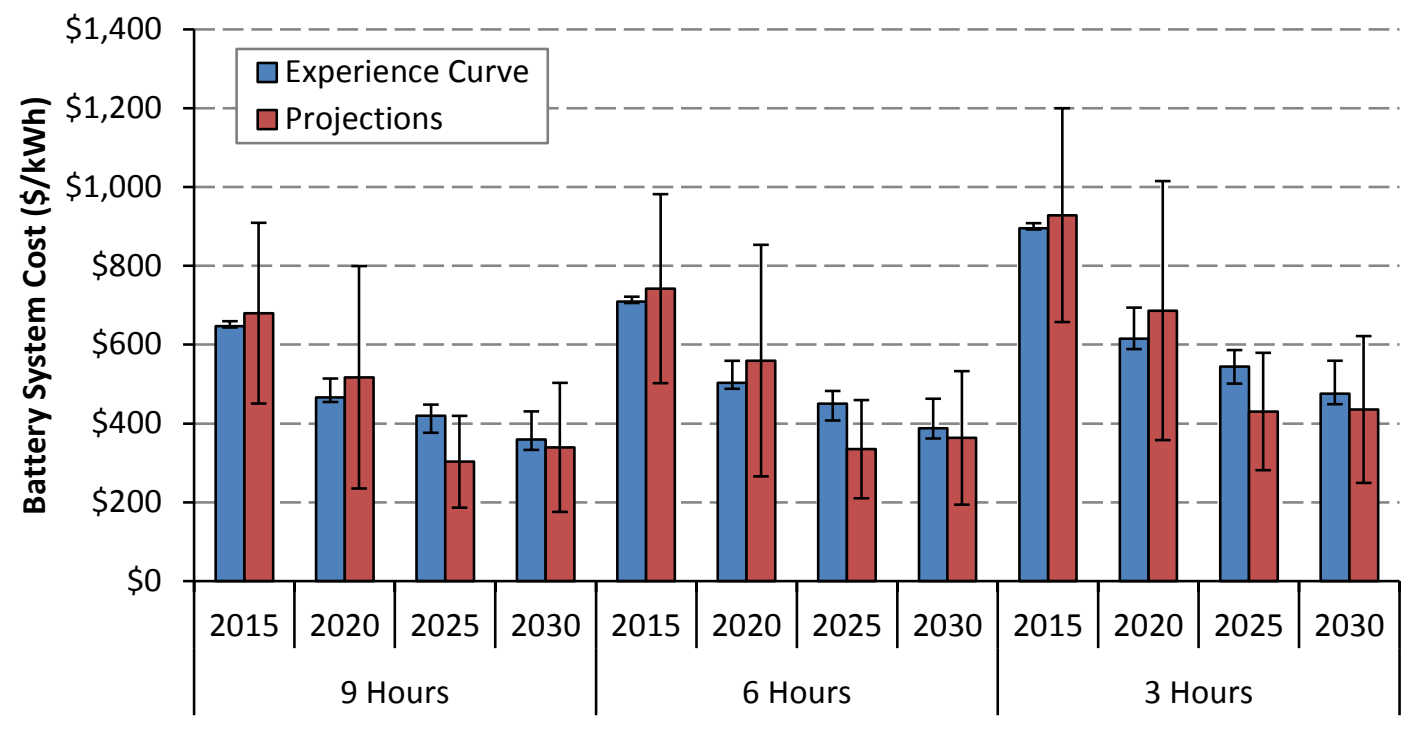

Figure 19. Projected battery system prices from historical experience curves and analyst estimates, 2015-2030

Mid case is shown with uncertainty bars representing the span of the low to high cases.

\subsection{CSP: Experience Curve}

CSP plant deployment has not yet reached the level of utility-scale PV. When we look at the capital costs of CSP plants around the world, as shown in Figure 20, without differentiating the technology, the location, or the company that built the plant, no clear pattern of cost reduction over time is observed.

\footnotetext{
${ }^{6}$ The high and middle cases using the projected approach increase slightly from 2025 to 2030 due to the increase in the number of Li-ion battery cell cost estimates in 2030.
} 


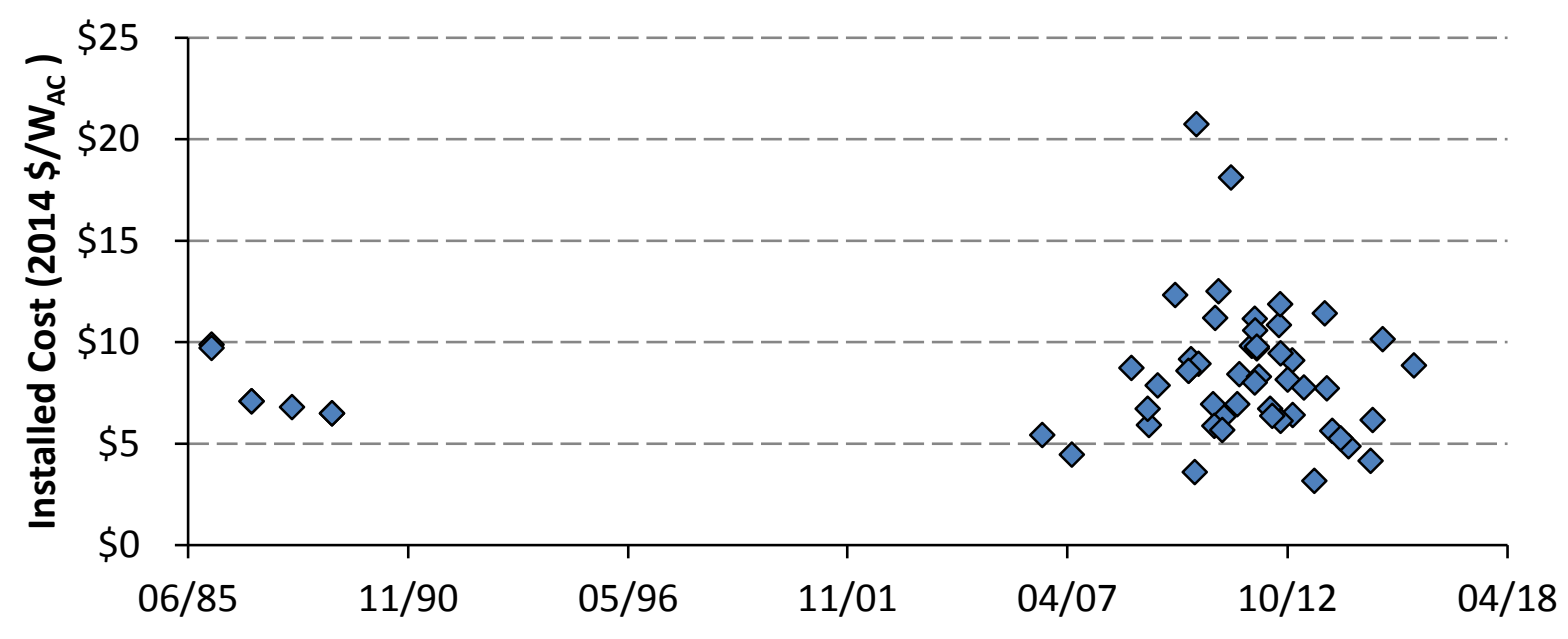

Figure 20. Installed cost of individual CSP plants over time

Sources: BNEF Power Project Database n.d.; Bolinger and Seel 2015

Individual factors can cause system pricing to vary considerably across plants, including inclusion of storage, technology type, location, and government policies. When controlling for project developer, country, and technology, a pattern of price reductions for CSP over time is observed, as shown in Figure 21.

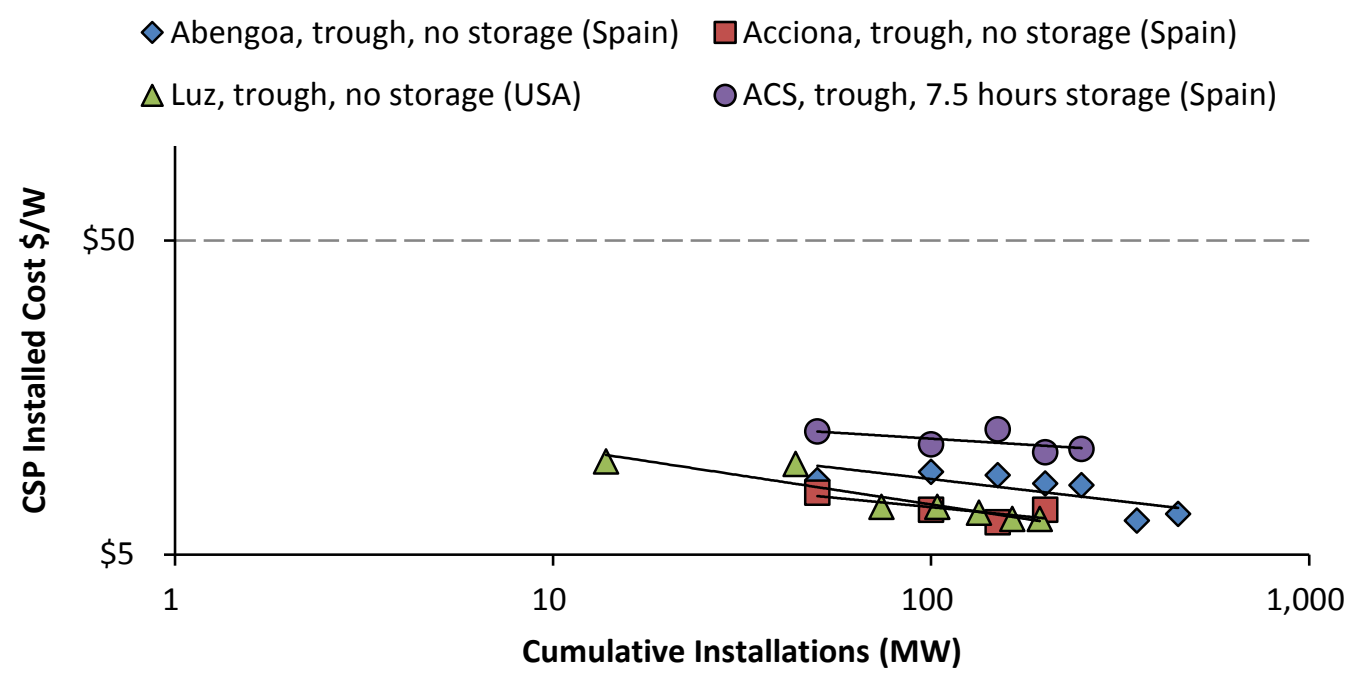

Figure 21. Experience curve of CSP projects, by developer, amount of storage, and location Source: Bloomberg New Energy Finance Power Project Database n. d.

For this subset of CSP plants, the data indicate that CSP plants have realized an experience rate between $5 \%$ and $12 \%$, with an average of $8.5 \%$. 
Global CSP deployment projections were collected from various sources, as shown in Figure 22. The high, mid, and low deployment cases were used to estimate CSP system prices using the average historical experience curves of $8.5 \%$, and a 2015 installed cost of $\$ 8,349 / \mathrm{kW}$ for a molten salt tower with nine hours of storage, $\$ 6,998 / \mathrm{kW}$ for a molten salt tower with six hours of storage, and $\$ 5,706 / \mathrm{kW}$ for a molten salt tower with hours of storage. ${ }^{7}$ Unlike with PV, global experience rates were used for CSP. The large global footprints CSP companies will likely lead to learning at the global level; thus, we model progress at the global level.

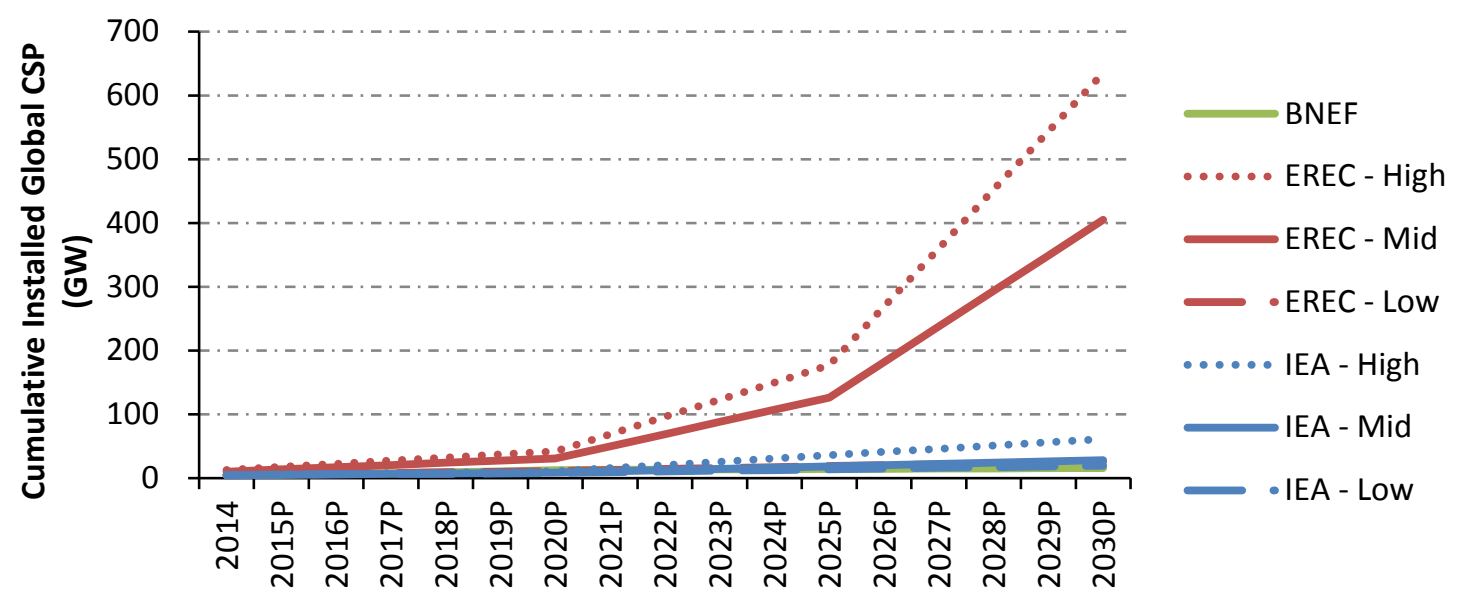

Figure 22. Global CSP deployment projections, 2014-2030

Sources: BNEF 2016; IEA 2015; Teske et al. 2015

Again, we use the standard power curve formula to calculate projected CSP system prices, starting from a 2015 benchmarked price of $\$ 8,349 / \mathrm{kW}$ for a 9-hour molten-salt tower CSP facility, $\$ 6,998 / \mathrm{kW}$ for a molten salt tower with six hours of storage, and $\$ 5,706 / \mathrm{kW}$ for a molten salt tower with three hours of storage. The results are summarized in Figure 24.

\footnotetext{
${ }^{7}$ System costs are based on component costs listed in Mehos et al. (2016) and are optimized for system configurations as described in Table 2 using NREL's System Advisor Model (SAM) Version 2016.3.14.
} 


\subsection{CSP: Analysts' Projections}

As we did with PV projections, to provide a counterpoint to the experience curve approach, we draw on a set of analysts' projections of U.S. CSP system prices through 2030. As shown in Figure 23, we use a wide-range of sources to develop a set of high, median, and low CSP system price projections.

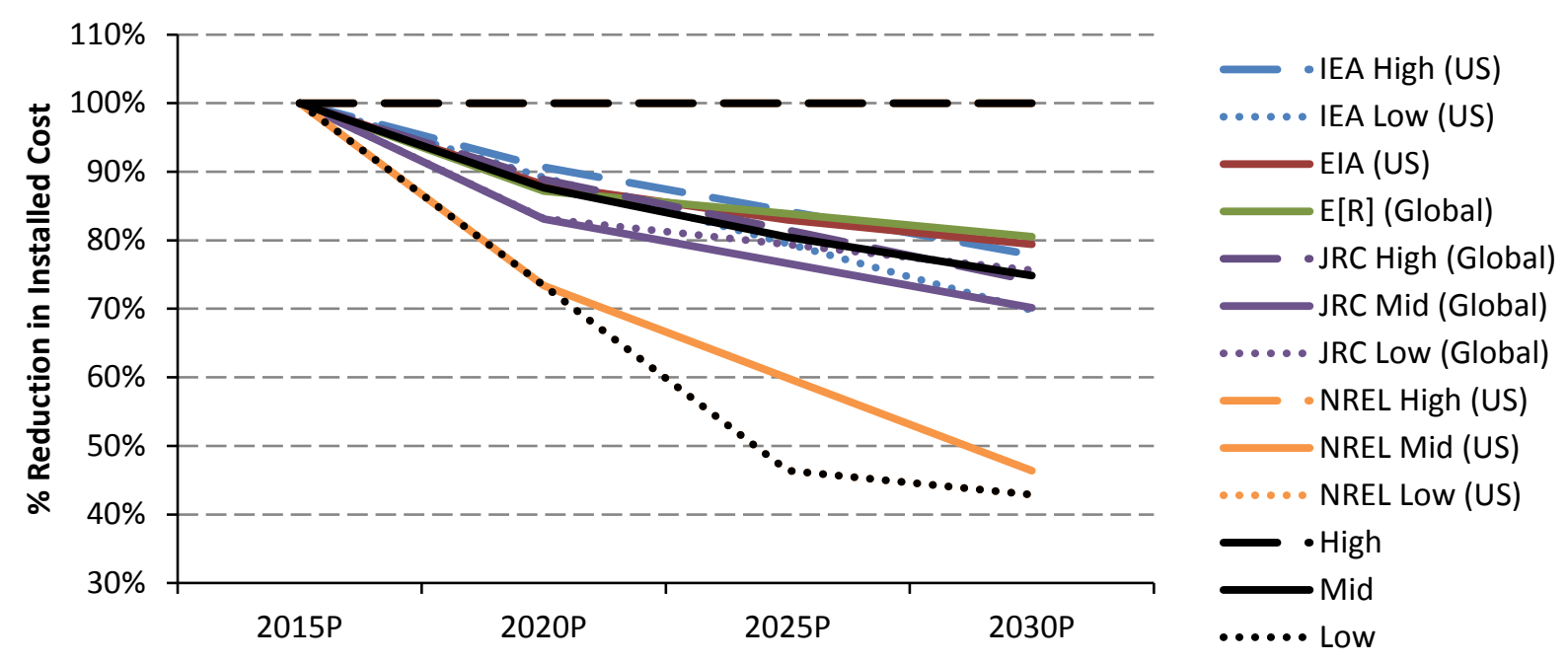

Figure 23. Projected CSP system prices, 2015-2030

Sources: Cole et al. 2016; EIA 2015; IEA 2015; JRC 2014; Teske et al. 2015

Projections of future CSP plant system costs are based on a collection of 10 system price projections from 5 separate institutions. The underlying price projections from these analyses represent a broad range of CSP technologies and configurations. Therefore, we normalize the analysis to a common starting point $(\$ 8,349 / \mathrm{kW}$ for nine hours of storage, $\$ 6,998 / \mathrm{kW}$ for six hours of storage, and $\$ 5,706 / \mathrm{kW}$ for three hours of storage, as were used for the experience curve approach) in order to focus on projected cost reduction of CSP technology. The maximum, median, and minimum projections of these adjusted values were taken for the high, mid, and low cases. To account for the temporal variation in price projections, estimates were made for every five years through 2030, with an assumed linear change between estimates. 


\subsection{CSP System Price: Comparison of Results Using Different Methodologies}

Figure 24 compares the mid-case CSP price for the experience curve approach and the compiled analysts' projections, with the uncertainty bars representing the span of the low to high cases. As show in the figure, the high analyst CSP system price projection is higher than the high price estimates using the experience curve approach (because it assumes no reduction in price from the 2015 baseline). However, the median and low analysts' projections result in lower projected system prices than the historical experience curve approach. Again, as with PV, we see industry analysts having more aggressive price projections than would be indicated by historical experience.

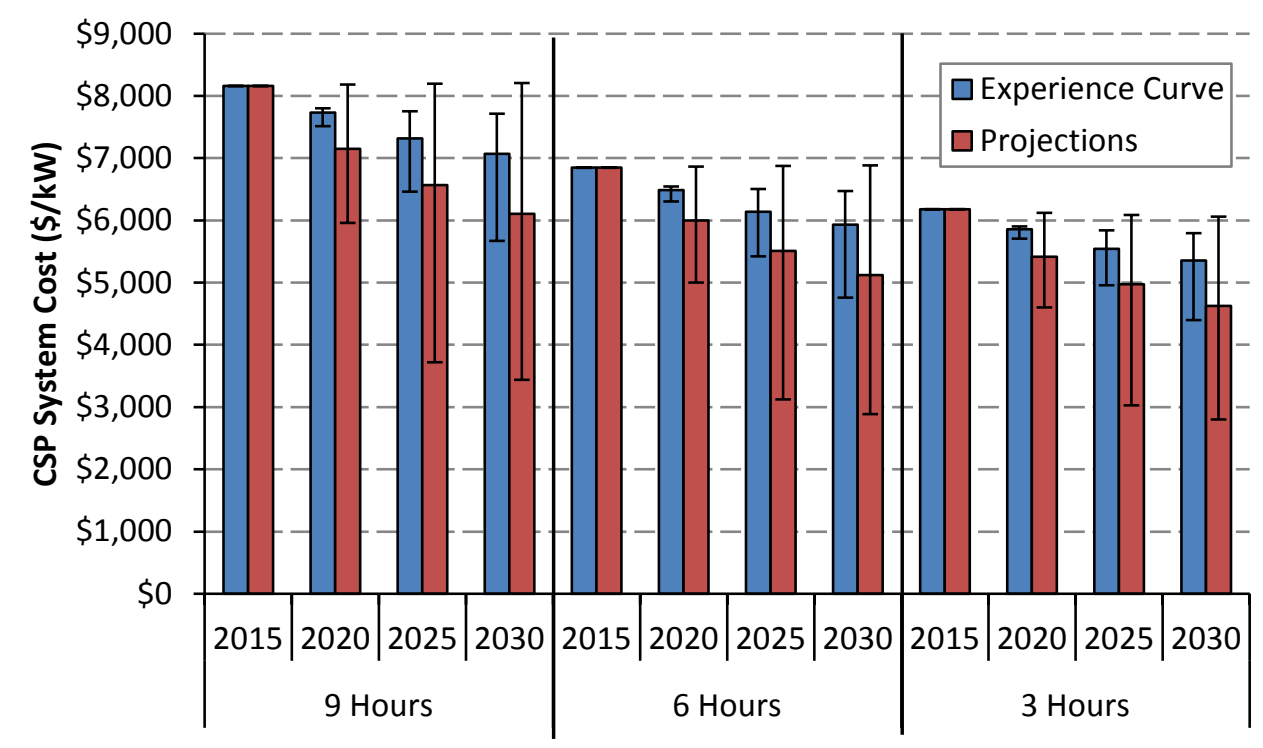

Figure 24. CSP system price projections from historical experience curves and analyst estimates, 2015-2030

Mid case is shown with uncertainty bars representing the span of the low to high cases. 


\section{Results of LCOE Analysis}

Using the system configurations described in Section 2, the assumptions in Table 3 below, and the experience curve and analysts' projections described in Section 3, we calculated the levelized cost of energy for CSP and PV with battery storage from 2015 to 2030 for three, six, and nine hours of storage. ${ }^{8}$

Table 3. Summary of LCOE Assumptions

\begin{tabular}{|c|c|c|}
\hline & CSP Tower & PV+ESS \\
\hline System size & $100 \mathrm{MWe}$ & $100 \mathrm{MWe}$ \\
\hline 2015 medium case system costs & $\begin{array}{l}\text { Experience curve and } \\
\text { analysts' projections } \\
9 \text { hours: } \$ 8,349 / \mathrm{kW} \\
6 \text { hours: } \$ 6,998 / \mathrm{kW} \\
3 \text { hours: } \$ 5,706 / \mathrm{kW}\end{array}$ & $\begin{array}{l}\text { Experience curve: } \\
9 \text { hours: } \$ 1,112 / \mathrm{kW} \\
6 \text { hours: } \$ 853 / \mathrm{kW} \\
3 \text { hours: } \$ 574 / \mathrm{kW} \\
\text { Analysts' projections: } \\
9 \text { hours: } \$ 1,105 \\
6 \text { hours: } \$ 844 / \mathrm{kW} \\
3 \text { hours: } \$ 563 / \mathrm{kW}\end{array}$ \\
\hline Discount rate (real) & $5.5 \%$ & $5.5 \%$ \\
\hline Lifetime & 30 years & 30 years \\
\hline Replacement & - & 1 or 2 battery replacements \\
\hline O\&M & $\begin{array}{l}\$ 65 \text { per kilowatt }(\mathrm{kW}) \text { per year } \\
\text { ( } 2015 \text { systems); straight-line } \\
\text { reduction to } \$ 40 / \mathrm{kW}(2030 \\
\text { systems) }\end{array}$ & $\begin{array}{l}\text { PV: } \$ 17 / \mathrm{kW} \text { (2014 systems); } \\
\text { straight-line reduction to } \$ 8 / \mathrm{kW} \\
\text { (2030 systems) } \\
\text { Batteries: } \$ 9 / \mathrm{kW}(2014 \\
\text { systems); straight-line } \\
\text { reduction to } \$ 7.6 / \mathrm{kW}(2030 \\
\text { systems) }\end{array}$ \\
\hline Annual degradation & & $\begin{array}{l}\text { PV system: } 1.0 \% \\
\text { Battery system: } 20 \% \\
\text { degradation at end of life }\end{array}$ \\
\hline
\end{tabular}

a Mehos et al. (2016)

b Cole et al. (2016)

c Naumann et al. (2015)

Figure 25 compares the mid-case LCOE calculations for PV with three hours of storage to CSP with three hours or storage; the uncertainty bars represent the span of the low to high cases. If three hours of storage is the desired or optimal level, the LCOE for PV+ESS tends to be lower than that of CSP; however, the ranges still overlap a great deal, particularly based on analysts' projections.

\footnotetext{
${ }^{8} \mathrm{We}$ developed a basic spreadsheet based model to calculate LCOE.
} 


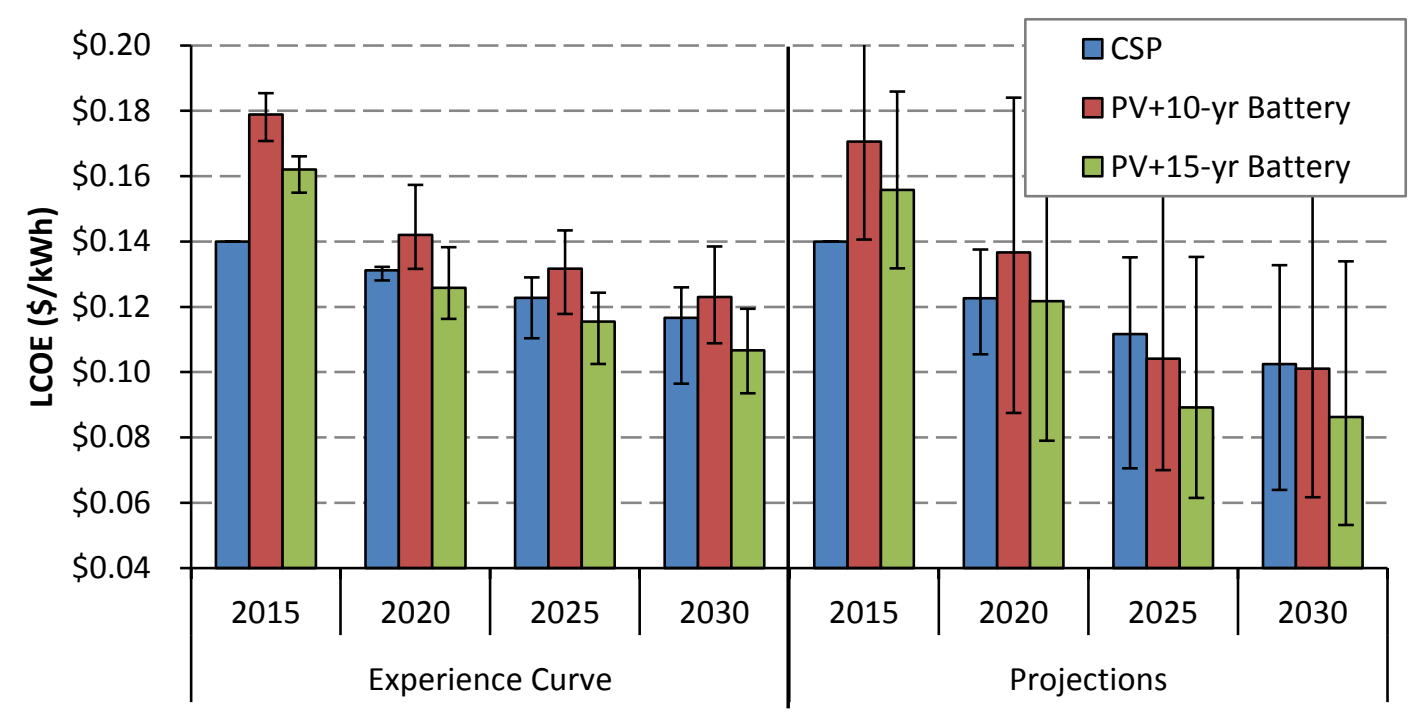

Figure 25. LCOE comparison: CSP versus PV (three hours of storage), 2015-2030

Mid case is shown with uncertainty bars representing the span of the low to high cases.

Figure 26 compares the mid-case LCOE calculations for PV with six hours of storage to CSP with six hours or storage; the uncertainty bars represent the span of the low to high cases. With six hours of storage, the gap between LCOE estimates narrows substantially; the increase in storage (compared to three hours of storage) decreases CSP costs while increasing PV+ESS costs.

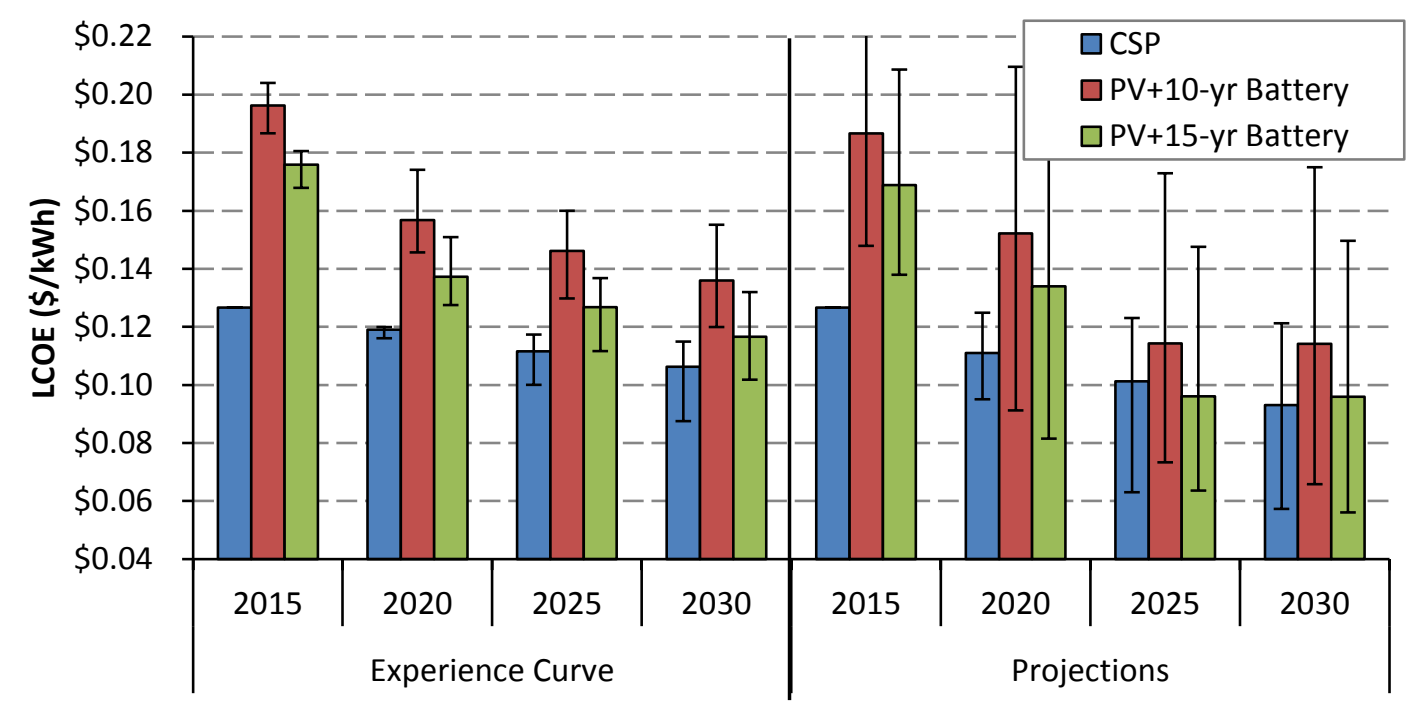

Figure 26. LCOE comparison: CSP versus PV (six hours of storage), 2015-2030

Mid case is shown with uncertainty bars representing the span of the low to high cases. 
Figure 27 compares the mid-case LCOE calculations for PV with nine hours of storage to CSP with nine hours or storage; the uncertainty bars represent the span of the low to high cases. If nine hours of storage is the desired or optimal level, the LCOE for CSP tends to be lower than that of PV+ESS; however, the ranges still overlap a great deal.

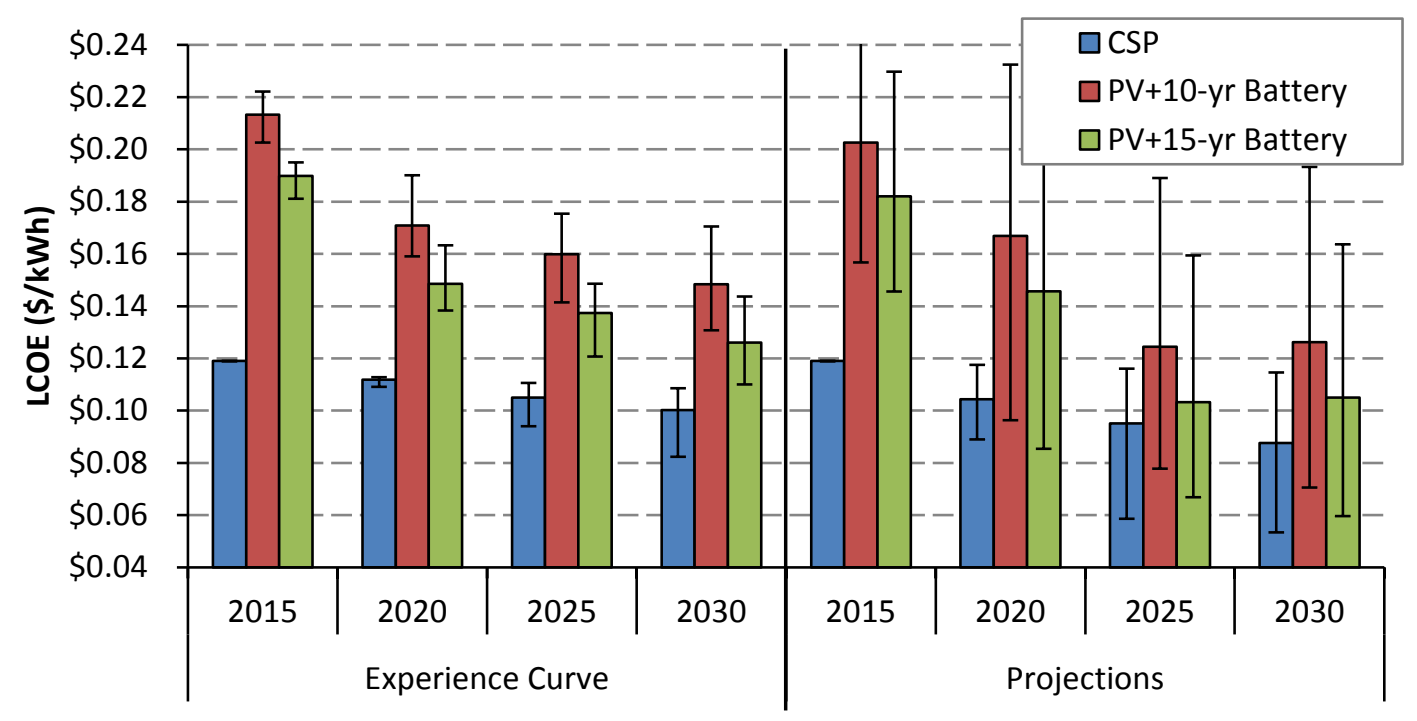

Figure 27. LCOE comparison: CSP versus PV (nine hours of storage), 2015-2030 


\section{Conclusion}

In this paper, we used a mix of experience curve projections and analysts' projections to estimate LCOEs for PV+ESS and CSP with thermal energy storage through 2030. We find that the relative competitiveness of each technology depends on how successfully they reach aggressive cost reduction targets. Given there is a great deal of uncertainty in the cost projections - for both technologies - we encourage the reader to focus on the range of results rather than a single point. There is also a great deal of uncertainty about what system configuration will make sense as solar penetration increases and the electricity system evolves over time.

As shown in Figures 26-28, the amount of storage desired is a key design parameter for PV and CSP, and it has a significant impact on which technology is likely to have a lower projected LCOE. If three hours of storage is the desired or optimal level, PV tends to produce a lower projected LCOE; if nine hours of storage is the desired or optimal level, CSP tends to have a lower projected LCOE. However, due to the overlap in projected LCOE ranges, a great deal of uncertainty about which technology will be more competitive in 2030 still exists.

Our analysis focused on comparing the relative costs of PV plus batteries and CSP with thermal energy storage, using LCOE as the main performance metric. However, this single metric ignores the value of the energy generated, which is critical to evaluating generation technologies within the context of the broader electricity system. We chose system configurations to make the plants as comparable as possible, by sizing the systems and the corresponding capacity factors to be roughly equal. This approach enables us to compare system configurations that would provide similar grid services at a high level (i.e, comparing a baseload plant with a baseload plant, and a peaking resource with a peaking resource). By comparing system configurations with similar amounts of storage, we also ensure that the plants compared will have similar capacity credits, or the ability to displace conventional capacity (for more information on capacity credits see Madaeni et al. 2013). Nonetheless, even with similar configurations, because of the nature of the storage technologies, CSP with thermal energy storage or PV plus batteries may be operated very differently depending on future grid configurations and electricity markets, potentially changing their relative value.

The biggest potential difference in value of energy generated is due to the very different manner in which energy is stored in the two systems. With CSP, the storage system is only able to store solar energy on-site, but with very high efficiency. Batteries are more flexible, with the ability to store grid energy, physically decoupled from the power generation assets, but they incur higher losses for stored energy. The actual difference in value that results from these differences strongly depends on many factors, including the level of solar penetration. At low penetration of solar energy, a relatively small amount of solar energy needs to be shifted due to the inherent coincidence of solar energy supply and energy demand patterns. In this case, for PV+ESS systems, it is more cost effective on most days to store less costly off-peak grid energy than solar energy. That is because at low levels of solar penetration, day time solar generation has a high value to the system, and there is a significant cost (real and opportunity) to storing solar energy during the day instead of storing lower cost off-peak generation and discharging that stored energy during the day. Previous analysis has demonstrated that at low penetration, the optimal solution is to use battery energy storage primarily to store off-peak energy at night, as opposed to on-peak solar energy (Denholm et al. 2013). The ability to utilize off-peak energy would tend to 
increase the value of PV+ESS relative to CSP+TES at low solar penetration. Additionally, as shown in Figure 25, PV+ESS is more likely to produce energy at lower costs than CSP+TES in the future with lower levels of storage. However, at higher levels of solar penetration, it will likely make sense to store an increasing fraction of mid-day solar generation for both PV+ESS and CSP+TES systems. In this operating regime, CSP has the inherent advantage that it can store a larger fraction of the solar energy than PV+ESS because of the larger power capacity of the storage system and higher efficiency. As shown in Figure 27, CSP tends to produce energy at lower costs than PV+ESS in the future with longer durations of storage. In this scenario, CSP provides a relative advantage.

Other factors can also influence the value of energy. For example, because they use conventional thermal generators, CSP plants have more constraints on their operation, require time to start up and ramp, have minimum run levels, and incur losses with each start. In contrast, PV with battery systems can respond very quickly to changing system needs. Thus, a PV+ESS system may be operated to avoid starting other power plants, and it can provide ancillary services including operating reserves. However, providing operating reserves from batteries may require more frequent cycling and result in shorter battery lifetime.

Overall, additional analysis is needed to comprehensively assess the relative value of PV+ESS and CSP+TES under different operating regimes. This type of analysis is complex, typically requiring detailed simulation models to estimate the optimized dispatch of the resource (Jorgenson, Mehos, and Denholm 2014). While evaluating the relative LCOE of PV+ESS and CSP+TES as we have done is a good first step, ultimately estimating the net value of different resources will be important for utilities and other system planners when evaluating the relative merits of competing solar-plus-storage technologies for meeting evolving system needs (Jorgenson et al. 2016). 


\section{References}

BNEF (Bloomberg New Energy Finance). n.d. Power Plants Database. Accessed June 15, 2015. . 2014. "Energy Storage Forecast, 2013-2020.” Logan Goldie-Scot. June 2, 2014.

—. 2015a. “H2 2015 US PV Market Outlook.” November 9, 2015.

—. 2015b. "Lithium-ion Battery Pack Outlook." Logan Goldie-Scot. November 10, 2015.

_. 2015. New Energy Outlook 2016: Global Overview. June 2016.

Bolinger, Mark, and Joachim Seel. 2015. Utility-Scale Solar 2014: An Empirical Analysis of Project Cost, Performance, and Pricing Trends in the United States. Berkeley, CA: Lawrence Berkeley National Laboratory. LBNL-1000917. September 2015.

Chase, Jenny. 2015. PV Market Outlook, Q3 2015. Bloomberg New Energy Finance. August 17, 2015.

Chung, Donald, Carolyn Davidson, Ran Fu, Kristen Ardani, and Robert Margolis. 2015. U.S. Photovoltaic (PV) Prices and Cost Breakdowns: Q1 2015 Benchmarks for Residential, Commercial, and Utility-Scale Systems. Golden, CO: National Renewable Energy Laboratory. NREL/TP-6A2064746. September 2015.

Cole, Wesley, Parthiv Kurup, Maureen Hand, David Feldman, Ben Sigrin, Eric Lantz, Tyler Stehly, Chad Augustine, Craig Turchi, Patrick O'Connor, and Connor Waldoch. 2016. 2016 Annual Technology Baseline: Discussion Draft. National Renewable Energy Laboratory. March 2016.

Denholm, Paul, Jennie Jorgenson, Marissa Hummon, David Palchak, Brendan Kirby, Ookie Ma, and Mark O'Malley. 2013. Impact of Wind and Solar on the Value of Energy Storage. Golden, CO: National Renewable Energy Laboratory. NREL/TP-6A20-60568. November 2013.

Feldman, David, Galen Barbose, Robert Margolis, Mark Bolinger, Donald Chung, Ran Fu, Joachim Seel, Carolyn Davidson, Naïm Darghouth, and Ryan Wiser. Photovoltaic System Pricing Trends: Historical, Recent, and Near-Term Projections: 2015 Edition. NREL/PR-6A2064898. August 25, 2015.

Fraunhofer ISE. 2015. Current and Future Cost of Solar Photovoltaics: Long-term Scenarios for Market Development, System Prices and LCOE of Utility-Scale PV Systems. Study on behalf of Agora Energiewende. 059/01-S-2015/EN. February 2015.

Gandolfi, A., J. Dumoulin-Smith, S. Oldfield, K. Liu, L. Yang, P. Hummel, and W. Li. 2015. Global Utilities Does the Future of Solar Belong with Utilities? UBS Global Research. June 3, 2015.

GTM Research. 2016. "Grid-Scale Energy Storage Balance of Systems 2015-2020: Architectures, Costs and Players." Ortiz, Luiz, and Manghani, Ravi. January 2016. 
GTM Research, and Solar Energy Industries Association. 2014. U.S. Solar Market Insight Report.

IEA (International Energy Agency). 2015. World Energy Outlook 2014. Paris: IEA. February 2015.

Izquierdo, Salvador, Carlos Montañés, César Dopazo, and Norberto Fueyo. 2010. "Analysis of CSP Plants for the Definition of Energy Policies: The Influence on Electricity Cost of Solar Multiples, Capacity Factors and Energy Storage.” Energy Policy 38(10):6215-6221. http://dx.doi.org/10.1016/j.enpol.2010.06.009.

Jorgenson, J., P. Denholm, M. Mehos, and C. Turchi. 2013. Estimating the Performance and Economic Value of Multiple Concentrating Solar Power Technologies in a Production Cost Model. Golden, CO: National Renewable Energy Laboratory. NREL/TP-6A20-58645. December 2013.

Jorgenson, J., P. Denholm, and M. Mehos. 2014. Estimating the Value of Utility-Scale Solar Technologies in California under a 40\% Renewable Portfolio Standard. Golden, CO: National Renewable Energy Laboratory. NREL/TP-6A20-61685. May 2014.

Jorgenson, Jennie, Mark Mehos, and Paul Denholm. 2016. "Comparing the Net Cost of CSPTES to PV Deployed with Battery Storage.” Proceedings of SOLARPACES 2015: International Conference on Concentrating Solar Power and Chemical Energy Systems, Cape Town, South Africa, October 13-16, 2015.

JRC (Joint Research Centre). 2014. ETRI 2014: Energy Technology Reference Indicator, projections for 2010-2050. European Commission: JRC Science and Policy Reports.

Lee, Brian, Patrick Archambault, Robert Koort, Michael Lapides, Ikuo Matsuhashi, and Masaru Sugiyama. 2015. The Great Battery Race: Framing the Next Frontier in Clean Technology - Electrical Energy Storage. Goldman Sachs Equity Research. October 18, 2015.

Madaeni, S. H. Seyed Hossein, Ramteen. Sioshansi, and P.aul Denholm. 2013. "Estimating the Capacity Value of Concentrating Solar Power Plants with Thermal Energy Storage: A Case Study of the Southwestern United States." IEEE Transactions on Power Systems 28(2) :1205-1215.

Mehos, Mark, Craig Turchi, Jennie Jorgensen, Paul Denholm, Clifford Ho, and Kenneth Armijo. Advancing Concentrating Solar Power Technology, Performance, and Dispatchability. Golden, CO: National Renewable Energy Laboratory. NREL/TP-5500-65688. May 2016.

Mints, Paula. 2015. Photovoltaic Manufacturer Capacity, Shipments, Price \& Revenues 2014/2015. SPV Market Research. Report SPV-Supply3. April 2015.

Navigant Research. 2013. Electric Vehicles Market Forecasts. Navigant Consulting. Published 4Q 2013. 
Naumann, Maik, Ralph Ch. Karl, Cong Nam Truong, Andreas Jossen, and Holger C. Hesse. "Lithium-ion Battery Cost Analysis in PV-household Application." 9th International Renewable Energy Storage Conference, IRES 2015.

Nykvist, Björn, and Nilson, Måns. 2015. "Rapidly Falling Costs of Battery Packs for Electric Vehicles." Nature Climate Change 5:329-332. March 23, 2015.

Osborne, Jeffrey, Thomas Boyes, and Moses Sutton. 2015. Dispatches from San Francisco: Highlights From InterSolar North America. Cowen \& Company Equity Research. June 16, 2015.

Roberts, Matt. 2015. "Energy Storage Markets and Policy. Energy Storage Association. Webinar hosted by UBS, September 2, 2015.

Rodriguez Labastida, Roberto, and Dexter Gauntlett. 2015. Distributed Solar PV: Market Drivers and Barriers, Technology Trends, Competitive Landscape, and Global Market Forecasts. Navigant Research. Q3 2015.

Rubin, Edward S., Inês M.L. Azevedoa, Paulina Jaramilloa, and Sonia Yehb. "A Review of Learning Rates for Electricity Supply Technologies.” Energy Policy 86(November 2015):198218.

SEIA (Solar Energy Industries Association), and GTM Research. 2015. U.S. Solar Market Insight: 2014 Year-in-Review. Washington, DC: Solar Energy Industries Association. March 2015.

Sharma, Ash. 2015. IHS Solar Market Intelligence. IHS. July 7, 2015.

Shiao, MJ . 2015. PV Balance of Systems 2015: Technology Trends and Markets in the U.S. and Abroad. GTM Research. August 2015.

Teske, Sven, Steve Sawyer, and Oliver Schäfer. 2015. Energy [r] evolution: A Sustainable World Energy Outlook 2015. Greenpeace International, Global Wind Energy Council, and SolarPowerEurope. September 2015.

UNFCCC (United Nations Framework Convention on Climate Change). 2016. Paris Declaration on Electro-Mobility and Climate Change \& Call to Action: Lima-Paris Action Agenda. http://newsroom.unfccc.int/media/521376/paris-electro-mobility-declaration.pdf

U.S. Energy Information Administration. 2015. Annual Energy Outlook 2015. June 2015.

—. 2016. Annual Energy Outlook 2016. May 2016.

Vartiainen, Eero, Masson, Gaëtan, and Christian Breyer. 2015. PV LCOE in Europe 2014-30:

Final Report, 23 June 2015. European PV Technology Platform Steering Committee: PV LCOE Working Group. June 2015. 